THE SUREACE MORPHOLOCY OF THIN AU FILNS DEPOSIIED ON SIRODU SLZSTRATES BY
SPUTTER DEPOSITION 


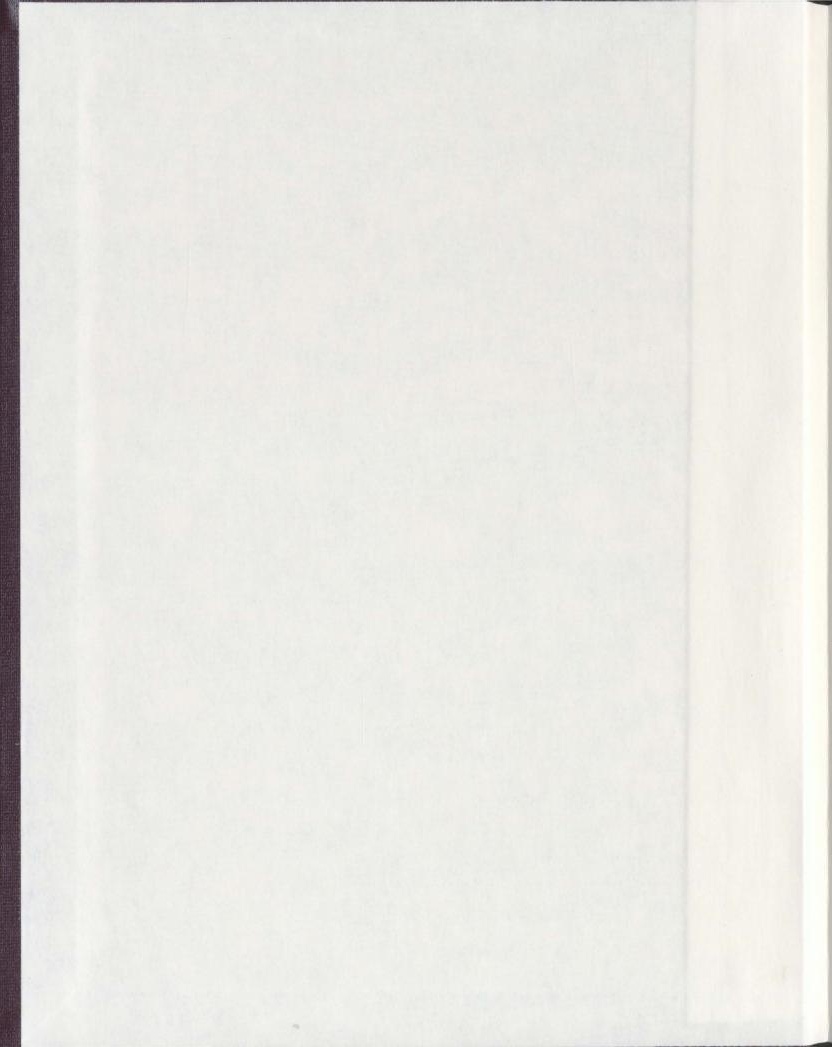






\title{
THE SURFACE MORPHOLOGY OF THIN AU FILMS DEPOSITED ON SI(001) SUBSTRATES BY SPUTTER DEPOSITION
}

\author{
By \\ C Sarah Ayoub \\ A Thesis submitted to the \\ School of Graduate Studies \\ In partial fulfillment of the requirements for the degree of \\ Master of Science \\ Department of Physics and Physical Oceanography \\ Memorial University of Newfoundland
}

April 2012

St. John's, Newfoundland 


\begin{abstract}
Thin $(100 \mathrm{~nm})$ gold films were deposited on $\mathrm{Si}(001)$ substrates by direct current magnetron sputtering. The effects of the deposition rate, the distance between the target and substrate, the substrate orientation, bias, temperature, and gas flow rate on the surface morphology of the Au film have been studied using atomic-force microscopy. It was observed that the deposition of $\mathrm{Au}$ on $\mathrm{Si}(001)$ followed the typical Volmer-Weber growth mode characterized, in the initial stages, by hemi-spherical grains distributed uniformly on the surface. Decreasing the target/substrate distance caused both the average grain diameter and height to increase. Decreasing the distance between the target and substrate from $19.5 \mathrm{~cm}$ to $5 \mathrm{~cm}$ and using a deposition rate of $0.1 \AA / \mathrm{s}$ produced samples in the second stages of the VW growth mode characterized by the coalescence of Au islands. Increasing the relative angle from $0^{\circ}$ to $90^{\circ}$ between the substrate and the substrate table caused the average grain diameter to decrease by approximately $8.7 \%$ and the average grain height to increase by approximately $52.3 \%$. Applying a high negative voltage to the substrate during the deposition caused a small decrease of approximately $10.2 \%$ in average grain size and a change of $26.2 \%$ to the average grain height. When the substrate temperature was lowered during the deposition process from 12 to $-11{ }^{\circ} \mathrm{C}$, a decrease of $21.6 \%$ was found in the average grain size while the height of the average grain increased by $44.7 \%$. By adjusting the above parameters it was possible to obtain samples with average grain size ranging from 26 to $180 \mathrm{~nm}$ with RMS roughness values ranging from 0.8 to $21 \mathrm{~nm}$. The results of this work provides an understanding for how to produce a wide range of surface morphologies of thin $\mathrm{Au}$ films on $\mathrm{Si}(001)$ for applications such as cantilever sensing and for producing bio-functionalized tips for atomic-force microscopy.
\end{abstract}




\section{ACKNOWLEDGEMENTS}

I first and foremost thank Allah for giving me the ability to do this work, making the difficult easy for me, and for the blessings he has bestowed upon me to make this a dream come true.

Next, I express my gratitude and appreciation to my supervisor, Dr. Luc Beaulieu, for guiding me in this project, and for all the attention, care, and time, he has spent with me. I have gained from him many skills in working in the lab and improving my writing for my thesis. It was truly a great honor for me to be under his supervision.

I express my thanks, and appreciation to Dr. Zain Yamani, who opened my mind and heart for Physics while in my undergrad. Without a professor like him, I doubt I would pursue higher education in this field.

I would also like to acknowledge King Abdulaziz University (KAU) for giving me this opportunity by funding me to pursue my master's degree. Thanks and gratitude go as well to the Saudi Cultural Bureau in Ottawa for their support.

I would also like to thank my beloved parents, Hayat and Abdulmajeed, who are always there for me whenever I need them. A hearty thanks to them for their continuous prayers for me, for their encouragement to continue my education in Canada, and for the love, strength, and inspiration that they have always given me. My parents went through hard times after I left them to achieve my dream. To them I will always be thankful and grateful until the last moment in my life. 
My deepest thanks to my beloved husband, Alan Hillier, who supported me in everything during my master's project. He is a miracle sent from God who has helped me overcome the hardships of being away from home. No words can express my appreciation to him for all the love he has given to me, for all the time he spent with me in the laboratory, and for proofreading my thesis and paper numerous times. I would not have finished this project without his support.

I also thank all my brothers and sisters, Abdulrahman, Abdullah, Mohammad, Maha, Ayah, Ghada, and Reema, for their encouragement and prayers. Special thanks to my brother, Abdulrahman, who accompanied me during my studies in Canada. We became best friends during this period. I am grateful to him for all the support and help he has been given me whenever needed.

Thanks to my uncle Dr. Mohi Ayoub (May Allah have mercy on him), who was always encouraging me to continue my graduate studies and who was looking forward to see me as one of his colleagues at KAU. Remembering him always gives me motivation and courage to be the best in my field. He will always be in my prayers and thoughts.

To my best friend and role model, Dr. Reem Altuwirqi, who was next to me in everything before I came to Canada, inspiring me to be stronger and to reach the highest levels of achievement, thank you! Many thanks to my friend Ilhan Aden for all the lovely chatting and caring that helped me in relieving the stress of pursuing this degree.

Finally, my thanks and regards to all those who supported me in any respect during the completion of this degree. 


\section{TABLE OF CONTENTS}

ABSTRACT ............................................................................................................ ii

ACKNOWLEDGEMENTS ............................................................................................ iii

Table of Contents .....................................................................................................................v

List of Figures................................................................................................................. vii

List of Tables ......................................................................................................................... ix

1 Introduction ............................................................................................................

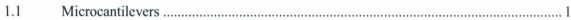

1.2 Motivation ............................................................................................................................... 2

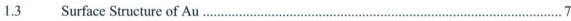

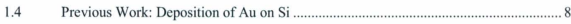

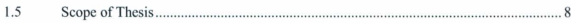

2 Thin Film: Deposition and Analysis.....................................................................10

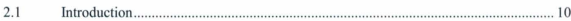

2.2 The Process of Thin-Film Deposition ............................................................... 10

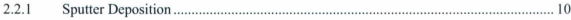

2.2.2 Quartz Crystal Monitor .......................................................................... 12

2.3 The Process of Thin-Film Growth ........................................................................... 13

2.3.1 Growth Modes ............................................................................................. 13

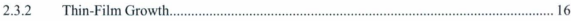

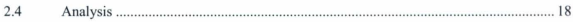

2.4.1 Theory of Atomic-Force Microscopy ……….............................................18

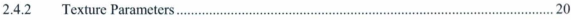

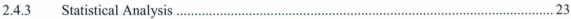

3 Experimental Setup and Method .......................................................................26

$3.1 \quad$ Experimental Setup ..........................................................................................26

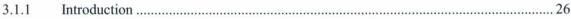

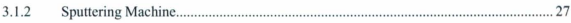

3.1.3 Dry-Lab …................................... 


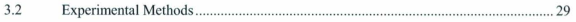

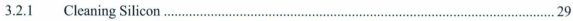

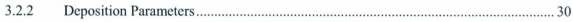

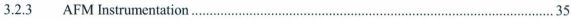

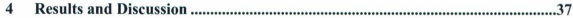

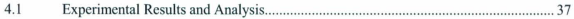

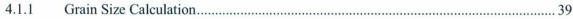

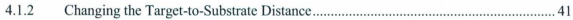

4.1.3 Changing the Substrate Orientation........................................................................ 45

4.1.4 Changing the Substrate Bias ..................................................................................... 48

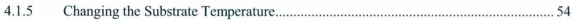

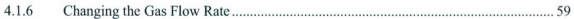

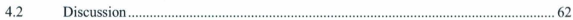

4.2.1 Changing the Target-to-Substrate Distance................................................................ 63

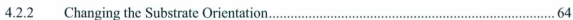

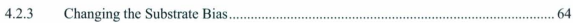

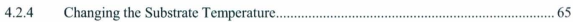

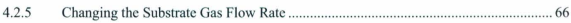

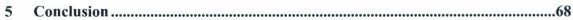

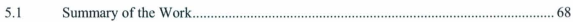

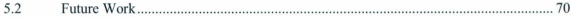




\section{LIST OF FIGURES}

\section{Chapter 1:}

Figure 1.1: Schematic representation of the deflection of a microcantilever.

2

Figure 1.2: The cantilever deflection and the surface stress induced by the formation of alkanethiol SAMs on the microcantilevers as a function of time for small- and largegrained Au.

\section{Chapter 2:}

Figure 2.1: Schematic of the sputtering system ......................................................... 11

Figure 2.2: Growth modes for thin films ................................................................. 14

Figure 2.3: The contact angle is a function of the surface energies between the substrate surface and the particle surface .............................................................................. 15

Figure 2.4: The microstructural stages of thin-film growth........................................ 17

Figure 2.5: Schematic of an atomic-force microscope ................................................. 19

Figure 2.6: Example of an AFM image and an extracted profile from an AFM image. .. 19 Figure 2.7: Schematic representation of the relationship between surface features and skewness 22

\section{Chapter 3:}

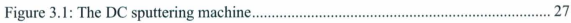

Figure 3.2: The glovebox used in this work. ........................................................... 28

Figure 3.3: Schematic diagrams illustrating the methods used to vary the deposition

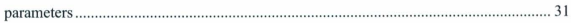

Figure 3.4: The cooling block and the threaded rods that are used to change the target-tosubstrate distance. 32 Figure 3.5: Orientation fixture that is placed on top of the cooling block and holds the samples to change their orientations with respect to the target. 33 
Figure 3.6: Plasma emitted during deposition with/without bias applied to the substrate. 34

Figure 3.7: A Peltier cooling device is attached to the cooling block to reduce the substrate temperature. 35

Figure 3.8: A molecular-imaging PicoSPM scanner, seen here with the AFM attachment.

\section{Chapter 4:}

Figure 4.1: $1 \times 1 \mu \mathrm{m}^{2}$ AFM image of $100 \mathrm{~nm}$ thick Au film grown on Si substrate at a deposition rate of $0.1 \AA / \mathrm{s}$, orientation of $0^{\circ}$, temperature of $12{ }^{\circ} \mathrm{C}$, bias of $0 \mathrm{~V}$, and target/substrate distance of $19.7 \mathrm{~cm}$. 38

Figure 4.2 : The steps used to identify the grains and calculate the average grain size by the Picolmage software. 40

Figure 4.3: The average grain size, RMS roughness, and other texture parameters of the Au films are plotted as a function of target/substrate distance 43

Figure 4.4: The average grain size, RMS roughness, and other texture parameters of the Au films plotted as a function of the substrate orientation 46

Figure 4.5: The average grain size, RMS roughness, and other texture parameters of the $\mathrm{Au}$ films plotted as a function of the bias. 51

Figure 4.6: $1 \times 1 \mu \mathrm{m}^{2}$ AFM images of Au films grown on $\mathrm{Si}$ substrates at deposition rate of $0.1 \AA / \mathrm{s}$, target/substrate distance of $5 \mathrm{~cm}$, and bias of $0 \mathrm{~V}$ 52 Figure 4.7: The average grain size, RMS roughness, and other texture parameters of the $\mathrm{Au}$ films plotted as a function of the temperature.

Figure 4.8: $1 \times 1 \mu \mathrm{m}^{2}$ AFM images of Au films grown on $\mathrm{Si}$ substrates at deposition rate of $0.1 \AA / \mathrm{s}$, target to substrate distance of $5 \mathrm{~cm}$, bias of $0 \mathrm{~V}$, and gas flow rate of 10 SCCM. 


\section{LIST OF TABLES}

\section{Chapter 1:}

Table 1.1: The SAMs and analytes studied on the smooth and nanostructured surfaces by each research group. 4

\section{Chapter 4:}

Table 4.1: T-Test analysis for samples produced using a deposition rate of $0.6 \AA / \mathrm{s}$ while changing the target/substrate distance during deposition 44

Table 4.2: T-Test analysis for samples produced at a deposition rate of $0.1 \AA / \mathrm{s}$ while changing the substrate orientation during deposition 47 Table 4.3: T-Test analysis for samples produced at different deposition rates and target/substrate distances while changing the substrate bias during deposition 53 Table 4.4: T-Test analysis for samples produced at different deposition rates and target/substrate distances while changing the substrate temperature during deposition ...58 Table 4.5: Analysis of samples synthesized under identical conditions with the exception of different flow rates. 60

\section{Chapter 5:}

Table 5.1: Changing the various deposition parameters allows a wide range of average grain size and RMS roughness to be achieved 


\section{INTRODUCTION}

\subsection{Microcantilevers}

Microcantilevers are small rectangular beams constructed of Si with dimensions ranging from 200-300 $\mu \mathrm{m}$ in length, $30-50 \mu \mathrm{m}$ in width, and $0.5-1 \mu \mathrm{m}$ in thickness. Microcantilevers can be made to be sensitive to specific target molecules by coating one surface with a functionalized self-assembled monolayer (SAM). Once functionalized, the microcantilevers become extremely sensitive sensors to physical changes, forces, chemicals and biological agents in various environments, providing detection ranges from as high as parts per trillion to parts per quadrillion [1]. These sensors provide high accuracy with quick response time all with a low power requirement, and at low cost. Two experimental modes of the microcantilevers exist: static and dynamic. The static mode measures the static deflection of the cantilever while the dynamic mode measures the shift in the resonant frequency of the microcantilever.

Microcantilever sensors have a simple functionality. When molecular interactions occur on the microcantilever surface between the immobilized receptors (sensor molecules) and the targets (analyte molecules), the cantilever will deflect, due to the change in the surface stress, see Figure 1.1. The deflection of the cantilever can be measured using an optical beam deflection system. This system includes a laser beam and a sensitive position detector. When the incident laser beam deflects from the cantilever 
onto the detector, the displacement of the cantilevers' free end can be obtained from the detector signal and used to determine the change in the surface stress.

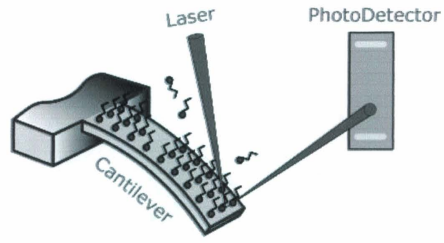

Figure 1.1: Schematic representation of the deflection of a microcantilever due to the change in the surface stress caused by the interaction between the receptor and the target molecules. Used with the permission [2].

Work on developing microcantilevers has been increasing in the last several years, due to their numerous applications in a variety of fields. However, before these sensors can be used reliably in a commercial application, there are still fundamental questions that need to be addressed such as the origin of the surface stress and the effects of secondary reactions. Another critical parameter that needs to be resolved is the relationship between the morphology of the Au film and the sensor sensitivity.

\subsection{Motivation}

Gold films are used extensively by the microcantilever sensor community to attach organic functionalized molecules (such as modified alkanethiols) onto silicon cantilevers. Gold is an ideal material because it is highly inert and does not oxidize at room 
temperature [3]. Modified alkanethiol molecules $\left(\mathrm{HS}\left(\mathrm{CH}_{2}\right)_{\Perp} \mathrm{X}\right)$ consist of an alkanetihol chain $\left(\mathrm{HS}\left(\mathrm{CH}_{2}\right)_{\mathrm{n}}-\right)$ with a receptive end group $(\mathrm{X})$. These molecules bind with a $\mathrm{Au}$ surface forming well-defined SAMs without the need for external stimuli. These endgroups are used to detect specific target molecules which define the selectivity of cantilever sensors.

A significant amount of research on cantilever sensors has focused on optimizing microcantilever surface stress by attempting to relate the sensitivity of cantilever sensors to the morphology of the thin Au film deposited on the cantilever. For microcantileverbased surface-stress sensing to become a viable technology, it is important to establish a better understanding of the effect of Au morphology (e.g., grain size, film roughness) on the sensitivity of cantilever sensors, as reported in the review by Ji et al. [4]. Unfortunately, the published results on this matter are varied and do not conclusively identify a definitive relationship between the Au morphology and the sensitivity of the sensor. Several researchers have shown that a rough or nanostructured surface of a film causes a greater response to the analytes than do smooth surfaces. This enhanced response is the result of rough surfaces having more surface area, which produces a larger number of binding sites to attract the analyte molecules. Lavrik et al. $[5,6]$, Tipple et al. [7], and Headrick et al. [8] have compared the response of cantilevers coated with smooth $\mathrm{Au}$ to dealloyed $\mathrm{Au}$. Table 1.1 summarizes the specific analytes detected by functionalized cantilever sensors coated with either smooth or nanostructured Au surfaces used by each research group. According to the results of these studies, the dealloyed Au is more efficient for enhancing the microcantilever surface stress in response to gas-phase hydrocarbon compounds. These cantilevers were observed to have a deflection two 
orders of magnitude larger than that obtained with the cantilevers coated with smooth $\mathrm{Au}$ films [5-7].

Table 1.1: The SAMs and analytes studied on the smooth and nanostructured surfaces by each research group.

\begin{tabular}{|c|c|c|}
\hline $\begin{array}{l}\text { Research } \\
\text { Group }\end{array}$ & Functionalized SAM Coating & Sensing Analytes \\
\hline Tipple et al. [7] & $\begin{array}{l}\text { Thiolated } \beta \text {-cyclodextrin (HM- } \beta \text { - } \\
\qquad \mathrm{CD}) \\
\text { and }(2,3-O \text {-diacetyl-6-O-tert-butyl- } \\
\text { dimeth-ylsilyl)- } \beta \text {-cyclodextrin }\end{array}$ & Dihydroxynaphthalene \\
\hline Lavrik et al. [5] & $\mathrm{HM}-\beta-\mathrm{CD}$ & $\begin{array}{l}\text { Protein A and biotin- } \\
\text { labeled albumin }\end{array}$ \\
\hline Lavrik et al. [6] & $\mathrm{HM}-\beta-\mathrm{CD}$ & Dimethylnaphthalene \\
\hline $\begin{array}{l}\text { Headrick et al. } \\
\qquad[8]\end{array}$ & $\begin{array}{l}\text { (2,3-O-Dimethyl-6-O-tert-butyl- } \\
\text { dimeth-ylsilyl)- } \beta \text {-cyclodextrin }\end{array}$ & $\begin{array}{l}\text { Dihydroxynaphthalene } \\
\text { and a series of volatile } \\
\text { organic compounds }\end{array}$ \\
\hline
\end{tabular}

Other researchers, however, have shown that smooth Au surfaces influence the surface stress more strongly than rough surfaces. Godin et al. [2] showed that the morphology of Au films influences the response of cantilever sensors to the detection of alkanethiols. This group studied the surface stress induced by the formation of alkanethiol SAMs on microcantilevers coated with different Au film morphologies. Figure 1.2 shows the cantilever deflection versus time for cantilevers coated with small 
grain $\mathrm{Au}$ and large grain Au when exposed to alkanethiols. The microcantilever coated with small grain $\mathrm{Au}$ (red curve) exhibited a smaller surface stress and deflection than the microcantilever coated with large grain Au (black curve). These results indicate that the microcantilevers coated with smoother Au (large grains) are more sensitive than those coated with rougher Au films (small grain size).

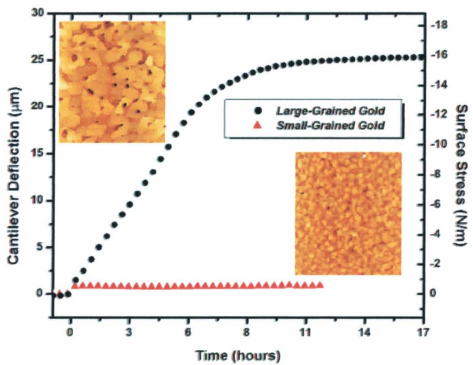

Figure 1.2: The cantilever deflection and the surface stress induced by the formation of alkanethiol SAMs on the microcantilevers as a function of time for small- and largegrained $\mathrm{Au}$. Used with the permission [2].

Tabard-Cossa et al. have reported similar results for the adsorption of thiol-based molecules [9]. However, these authors found that the average grain size of the Au surface did not strongly influence surface-stress changes induced by the adsorption of anions. Rather, they discovered that the surface stress is more dependent on the continuity of the 
Au sensing surface. The authors were careful to point out, however, that this result cannot be generalized to other reaction mechanisms. Lastly, Mertens et al. [10] studied the effect of the deposition rate of the Au films on the surface stress induced by the adsorption of alkylthiols, and found no relationship between the cantilever deflection and the Au film roughness.

It is clear from the previously discussed results that it has not been possible to conclusively identify a relationship between the Au morphology and the sensitivity of cantilever sensors. One possible reason for this discrepancy in the literature is that different reaction mechanisms were used to investigate the relationship between the $\mathrm{Au}$ roughness and the sensor sensitivity. Different reaction mechanisms may be more sensitive to rough Au films, whereas others may be more sensitive to smoother films. Therefore if this is the case, it would be useful to develop a method to control the morphology of thin Au films on $\mathrm{Si}(001)$ cantilevers in order to increase cantilever sensors sensitivity for detecting targets through specific reaction mechanisms. For this purpose, we investigated the effects of various substrate parameters on the morphology of thin $\mathrm{Au}$ films deposited on $\mathrm{Si}(001)$ substrates by sputter deposition. The morphology of Au films was characterized by atomic-force microscopy, and the resulting images were analyzed using a standard software package. 


\subsection{Surface Structure of Au}

One important component of linking surface morphology with a cantilever sensor is the surface structure of Au. The effects of the surface structure of Au, whether it forms as a flat extended surface or an assembly of faceted particles, on the self-assembly of alkanethiols have been studied to determine their properties, surface structure, chain packing, and chemical reactivity [11-13]. It has been reported that the adsorption geometry of such monolayers on the $\mathrm{Au}(111)$ surface is hexagonal-close-packed $[12,14$ 16]. This is, in general, the most stable configuration for thiol molecules to form on, as the single thiol molecules binds in the hollow of three adjacent Au surface atoms. In the case of the $\mathrm{Au}(100)$ surface, the thiol molecules attach to the hollow site of four $\mathrm{Au}$ atoms. Cheng et al. [12] studied the effect of the crystal orientation of Au on the interfacial bonding strength of the SAM-coated Au-epoxy and Au-Au systems, and found that the bonding strength of the SAM showed a strong dependency on the crystal orientation of the Au surface. They performed a comparative study between three different SAMs of alkanethiolates on both substrates of $\mathrm{Au}(100)$ and (111), and found that Au with crystal orientation of (111) exhibited greater SAM/epoxy interfacial bonding strength of the SAM-coated Au-epoxy system than Au with crystal orientation of (100). However, the opposite result was exhibited for SAM-coated Au-Au joint. Furthermore, Cheng et al. reported that crystal orientations of $\mathrm{Au}$ would affect on the atom arrangements of the monolayers. Even though it is clear that the surface structure of $\mathrm{Au}$ can have an effect on the self-assembly of alkanethiols, it appears that whether Au forms as a flat extended surface or as an assembly of faceted particles, the main parameter that affects the sensitivity of the microcantilevers is the morphology of the Au surface. 
Through a study of the equilibrium structures and thermodynamic properties of dodecanethiol self-assembled monolayers on small and larger Au nanocrystallites, Luedtke et al. [17] found that on extended flat $\mathrm{Au}(111)$ and $\mathrm{Au}(100)$ surfaces, the smaller the Au terraces, the lower the disordering temperature of the SAM. Hence, the less stable the thiol molecules are on the substrate due to the orientation of the alkyl chains (lying down or standing up) the less reproducible the sensor.

\subsection{Previous Work: Deposition of $\mathrm{Au}$ on $\mathrm{Si}$}

Several studies have been conducted on the deposition of $\mathrm{Au}$ on various substrates. For example, the effect of sample annealing, the use of elevated substrate temperature during deposition, and the variation of film thickness have been studied [18-24]. In general, increasing the deposition temperature and/or the annealing temperature (post deposition) and/or the film thickness increases the grain size and the RMS roughness. However, an investigation into the effects of the substrate orientation, the distance between the substrate and target, substrate bias, and application of low substrate temperature during sputtering Au films on Si has not, to our knowledge, been reported in the literature.

\subsection{Scope of Thesis}

The purpose of this thesis is to report the effects of different sputter deposition parameters on the surface morphology of thin Au films deposited on $\mathrm{Si}(001)$ substrates for the purpose of developing a method to control the roughness of Au films. The thesis is organized as follows: Chapter 2 discusses the details of the thin-film deposition and 
growth. This chapter also reviews the analytical methods and texture parameters used to characterize the surfaces of thin films. Chapter 3 presents the experimental setup that was used to deposit thin Au films on Si substrates, how the Si substrates were prepared prior to sputtering, and the experimental methods that were used to vary the deposition parameters. Chapter 3 finishes with a short description of the atomic-force microscope and imaging technique used for characterizing the samples. Chapter 4 discusses the results and analysis of the samples synthesized and outlines the correlation between the deposition parameters, grain size, and surface roughness. Finally, concluding remarks of this work and suggestions for future work are given in Chapter 5 . 


\section{ThIN FILM: DEPOSITION AND ANALYSIS}

\subsection{Introduction}

Thin films have become an integral part of numerous scientific applications, such as sensors, electronic packaging, integrated circuits, optical devices, and protective and decorative coatings [25]. A thin film is a solid layer that ranges in thickness from a few nanometers to many micrometers. The properties of thin films are affected by the morphology and microstructure. Therefore, understanding the thin-film deposition process is essential for controlling the properties of thin films for specific applications. Sputter deposition is one of many methods used to make thin films. This chapter will describe the sputter deposition process, discuss how to image thin films by atomic-force microscopy, and characterize them using texture parameters.

\subsection{The Process of Thin-Film Deposition}

\subsubsection{Sputter Deposition}

The sputter deposition system used in this work was a dc magnetron sputtering machine by Corona Coaters (Vancouver, BC, Canada). The system consists of several main elements such as a vacuum chamber, a pumping system, power supplies, a target material, and a substrate. The target material acts like the cathode of an electrical circuit as it is held at a high negative dc voltage. The substrate, which acts as the anode, is 
placed opposite the target, as shown in Figure 2.1a). These electrodes are housed in an evacuated chamber called the sputtering chamber. The sputter deposition process begins when argon ions enter the sputtering chamber and are accelerated towards the target as a result of an applied high negative potential (see Figure 2.1a). As the ions collide with the target, they expel target atoms through a transfer of momentum (see Figure 2.1b). The target atoms (black circles) move away from the target in all directions including the direction of the substrate. As the target atoms accumulate on the substrate, they start to form a thin film [26].

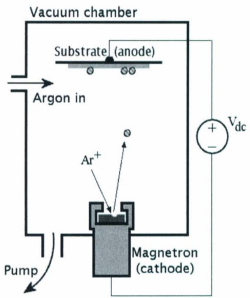

(a)

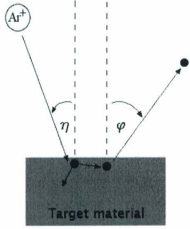

(b)

Figure 2.1: (a) Schematic of the sputtering system. (b) Interaction of an $\mathrm{Ar}^{+}$ion with a surface expelling target atoms (black circles) from the target, where $\eta$ is the angle between the incident direction of the $\mathrm{Ar}^{+}$ion and the direction normal to the target surface, and $\varphi$ is the angle between the sputtered atom and the direction normal to the target surface. Used with the permission [27]. 


\subsubsection{Quartz Crystal Monitor}

Film properties, such as resistivity, capacitance, optical wavelength, and reflectivity, can be altered by the film thickness [28]. Other factors, such as crystal structure, adhesion, and stress, can be affected by the rate of deposition. In this work, a quartz crystal monitor (QCM) was used to measure the film thickness and the deposition rate. A QCM uses the piezoelectric effect to measure the change in resonant frequency of the surface of the crystal. When an if voltage is applied to the quartz crystal, the latter oscillates at its natural resonant frequency. When a film is deposited onto the crystal, the oscillation frequency changes. The change in frequency is related to the change in mass of the material deposited on the crystal according to the Sauerbrey equation, which is applicable only on uniform, rigid, and thin films [28]:

$$
\frac{\Delta m}{A}=\frac{\Delta f\left(\mu_{q} \rho_{q}\right)^{1 / 2}}{2 f_{o}^{2}},
$$

where $\Delta f$ is the measured frequency shift, $f_{o}$ is the initial frequency of the quartz crystal prior to a mass change, $\Delta m$ is the mass change, $A$ is the piezoelectrically active area, $\rho_{q}$ is the density of quartz, and $\mu_{q}$ is the shear modulus of quartz. Equation 2.1 shows that the shift in frequency due to the film deposition on the crystal is proportional to the deposited mass per unit area of the film. The mass per unit area is related to the film thickness and film density, $\frac{\Delta m}{A}=h_{f} \rho_{f}$. 


\subsection{The Process of Thin-Film Growth}

\subsubsection{Growth Modes}

During the initial nucleation stage, three characteristic growth modes are observed: Volmer-Weber (VW) mode, Frank-van der Merwe (FM) mode, and Stranski-Krastanov (SK) mode. These growth modes can be distinguished by the thermodynamic parameters of the deposited material and the substrate surface. The VW mode can be described as an island type, the FM mode as a layer type, and the SK mode as a mix of layer and island types [29]. These modes are shown in Figure 2.2. In the FM growth mode, the deposited grains are attracted more strongly to the substrate surface than to themselves; thus, the nucleation density is high and the islands grow two-dimensionally until the substrate surface is covered by a complete monolayer. In the VW growth mode, however, the deposited atoms are more strongly bound to each other than to the substrate surface; therefore, the islands grow three-dimensionally and thereby minimize the interaction between the deposited grains and the substrate surface. The SK mode is the intermediate mode that occurs when the deposited grains are initially strongly bound to the substrate surface. After the substrate surface is covered by a few monolayers, the film growth switches to three-dimensional islands because of a strain introduced by a lattice mismatch between the film and the substrate surface [30]. 
a) Volmer-Weber

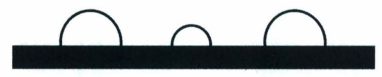

b) Stranski-Krastanov

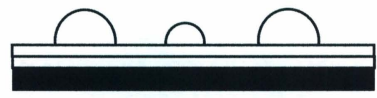

c) Frank-van der Merwe

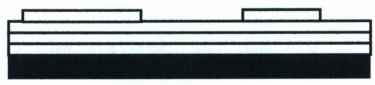

Figure 2.2: Growth modes for thin films: a) Volmer-Weber, b) Stranski-Krastanov, and c) Frank-van der Merwe. 
The generation of different morphologies is governed by the surface energy of the thin film, $\gamma_{f}$, the surface energy of the substrate, $\gamma_{s}$, and the interfacial energy between thin the film and the substrate, $\gamma_{f s}$. Another factor that affects the surface morphology is the contact angle (see Figure 2.3). The contact angle is a function of the surface energies between the substrate surface and the particle surface given by Young's equation [31]:

$$
\cos \theta=\frac{\gamma_{s}-\gamma_{f s}}{\gamma_{f}}
$$

Figure 2.3: The contact angle, $\theta$, is a function of the surface energies between the substrate surface and the particle surface.

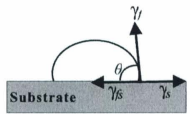

For the VW mode, $\theta>0$, and therefore island growth occurs. The surface substrate has a lower free energy than the surface of the thin film and the interfacial energy between the thin film and substrate. The interfacial energy can be neglected because it is substantially smaller than the surface energies of the substrate and thin film. As a result, the VW growth mode will be promoted when the surface energy of the thin film is greater than that of the substrate [30].

For the FM mode, $\theta=0$, and therefore the layer growth mode will be predominant. The FM-mode growth will occur when the deposited material has a lower energy than the substrate surface. Thus, the film will wet the substrate surface [30].

For the SK mode, the contribution of the induced strain due to lattice 
mismatch increases the surface energy of the thin film as the film thickness increases. Layer growth occurs when $\theta=0$, and island growth occurs when $\theta>0$ for thicker films [30].

\subsubsection{Thin-Film Growth}

The target atoms adsorb on the substrate after losing their velocity component normal to the surface. The target atoms then form larger clusters by interacting with each other. A portion of target atoms may re-evaporate if they are not in thermal equilibrium with the substrate surface. Clusters eventually become thermally equilibrated with the substrate surface after reaching a critical size [29], at which point the clusters enter the nucleation stage. The nucleation stage is the first stage of thin-film growth, as shown schematically in Figure 2.4. In the next stage, the nuclei grow larger and merge into larger clusters, called islands, which leads to a decrease in the area occupied by the separate nuclei and the formation of a discontinuous film structure. When the islands grow sufficiently and begin touching each other, the coalescence stage of thin-film growth occurs. At this point, the film shape changes completely and the size of islands increases, resulting in a network of channels [32]. As the channels and holes are filled during further deposition, the film structure changes from a discontinuous structure to a continuous film. The latter stage may occur only when the film thickness reaches several hundred angstroms [31]. 


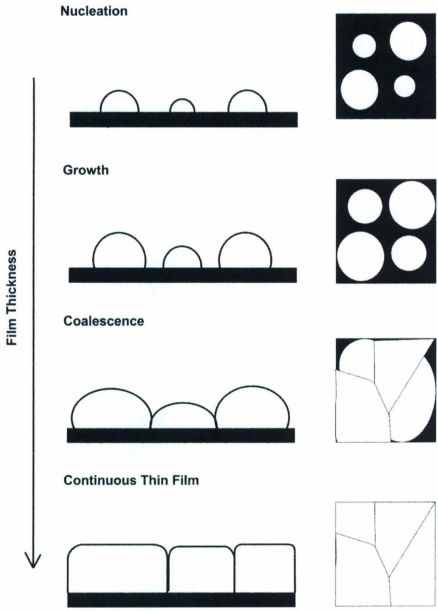

Figure 2.4: The microstructural stages of thin-film growth. 


\subsection{Analysis}

Characterizing the film is necessary to quantify the surface morphology and roughness. Control of these parameters is important for the manufacture of electronic devices, multi layers, and ultra-thin films. The surface morphology of thin films generally depends on the grain size, surface texture, and film thickness. In this work, surface morphology was characterized using atomic-force microscopy (AFM).

\subsubsection{Theory of Atomic-Force Microscopy}

AFM is an analytical method that resolves the surface topography of thin films from microns to angstroms. AFM is a process where a sharp tip, which is mounted at the free end of a microcantilever, is scanned over the sample surface. Figure 2.5 shows a schematic of a typical AFM system which consists of a microcantilever probe with a sharp tip, a piezoelectric actuator, and a position-sensitive photo-detector (PSD). AFM systems are operated in three modes: contact mode, non-contact mode, and tapping mode. In this work, constant-force contact mode AFM was used to study the morphology of thin Au films on Si.

In constant-force contact mode AFM, the tip is pushed against the sample surface to create a repulsive force that results in the deflection of the cantilever. The deflection can be detected by capacitive, piezoresistive, or optical means. A piezoelectric tube elongates or contracts to maintain a constant force of the cantilever on the surface. The change in length of the piezo is displayed as a function of the lateral position of the cantilever to provide a 2-dimensional profile of the surface topography. Figure 2.6 shows 
an example of an extracted profile measurement from an AFM image. A 3-dimensional representation of the surface topography is generated by repeating the collection of traces throughout the sample [33].

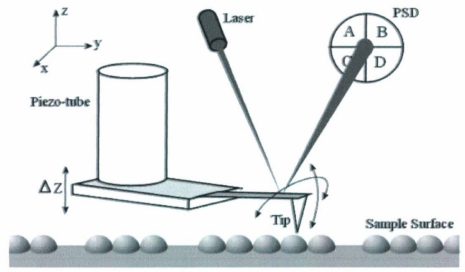

Figure 2.5: Schematic of an atomic-force microscope, including the piezo-tube actuator, the cantilever, the laser focuser, position-sensitive photodetector (PSD) and sample. Used with the permission [27].

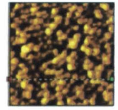

(a)

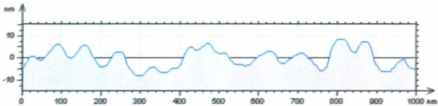

(b)

Figure 2.6: Example of a) an AFM image, and b) an extracted profile from an AFM image. 


\subsubsection{Texture Parameters}

In this work, the morphology of the thin Au films was characterized using the following topological parameters based on the International Organization of Standards (ISO). The root-mean-square (RMS) roughness, $S_{q}$, was computed using the following equation:

$$
S_{q}=\sqrt{\frac{\sum_{i=1}^{N}\left(z_{i}-\mu_{z}\right)^{2}}{N}}
$$

where $z_{i}$ is the surface height, $\mu_{z}$ is the mean value, and $N$ is the total number of points of the surface. The RMS roughness is the most commonly used measure for characterizing the surface roughness of thin films. Unfortunately, this parameter only provides a value of the standard deviation of the surface height and provides no correlation between the surface features and the size of the sample or the frequency at which the surface features occur. As a result, different surfaces may lead to identical values of RMS roughness [34]. For this reason, other surface-texture parameters must be included when surfaces are characterized to provide further insight into the topographic changes of the sample. The following are texture parameters that were used to characterize the surface roughness.

The skewness, Ssk, and the kurtosis, $S k u$, were also used to analyze the samples synthesized in this work. The skewness and the kurtosis, also known as the third and fourth moment of the distribution, provide a rough understanding of the shape of the height distribution profile of a sample. The skewness is defined as:

$$
S s k=\frac{\sum_{i=1}^{N}\left(z_{i}-\mu_{z}\right)^{3}}{N \sigma^{3}},
$$


where $\sigma$ is the standard deviation of the surface height equal to the RMS roughness given by equation 2.3. The skewness gives a description of the level of asymmetry of the distribution of the surface height. This parameter is sensitive to the level of peaks and valleys. Surfaces with a predominance of high peaks should lead to a positive skewness indicated by a distribution that is heavier on the right-hand side. Surfaces with a predominance of deep valleys should have negative skewness because this leads to a distribution that is heavier on the left-hand side (see Figure 2.7) [35, 36].

The kurtosis, which is defined as:

$$
S k u=\frac{\sum_{i=1}^{N}\left(z_{i}-\mu_{z}\right)^{4}}{N \sigma^{4}},
$$

gives an estimate of the width or peakness of a distribution. For a perfect Gaussian distribution, the kurtosis is 3 . For a surface with numerous high peaks and low valleys, the kurtosis is larger than 3 , and the distribution of the surface height is sharp and narrow. For a surface with few high peaks and low valleys, the distribution of the surface height is broad, which leads to a kurtosis value of less than $3[35,36]$. 
a)

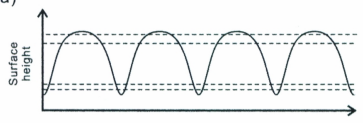

c)

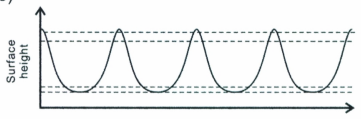

b)

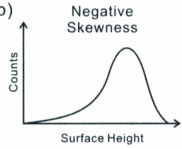

d)

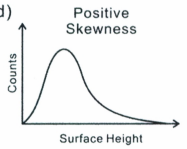

Figure 2.7: Schematic representation of the relationship between surface features and skewness. a) Broad peaks and narrow valleys lead to a distribution b) that is skewed toward the right, thereby providing a negative skewness. c) A surface that has sharp peaks and broad valleys leads to a distribution d) that is shifted to the left, thereby giving a positive skewness.

The RMS slope, $S d q$, was also used to analyze surfaces. $S d q$ is the root-meansquare of all of the surface slopes at every point within the sampling area [37]. Sdq is defined by

$$
S d q=\sqrt{\frac{1}{(M-1)(N-1)} \sum_{j=2}^{N} \sum_{i=2}^{M}\left[\left(\frac{z\left(x_{i}, y_{j}\right)-z\left(x_{i-1}, y_{j}\right)}{\Delta x}\right)^{2}+\left(\frac{z\left(x_{i}, y_{j}\right)-z\left(x_{i}, y_{j-1}\right)}{\Delta y}\right)^{2}\right]},
$$

where, in this equation, the summation is separated over both $x$ and $y$ directions. As the surface roughness increases, the $S d q$ increases due to the increased number of large slopes. 
A useful measure of the roughness of a sample is the surface-area ratio, $S d r$, which represents the percentage of the excess surface area of the sample relative to the base, defined as [37] (see appendix A):

$$
S d r=\left(\frac{\text { Area of the Sample }- \text { Area of the substrate }}{\text { Area of the substrate }}\right) \times 100 \% \text {. }
$$

The $S d r$ is one of the few characterization functions that give an estimate of the surface roughness relative to the actual size of the sample. Clearly, when the $S d r$ values approach $0 \%$, the surfaces are extremely flat. When the $S d r$ is notably greater than $0 \%$, the surface becomes rougher.

\subsubsection{Statistical Analysis}

Statistical analysis is necessary for analyzing the surface morphology of Au films to find the statistical significance of changing the sputtering parameters and to confirm their effects on the films. For example, it is useful to determine if there is a significant difference between two mean values of the average grain size when the target/substrate distance is changed from $19.7 \mathrm{~cm}$ to $5 \mathrm{~cm}$ during the sputtering of $\mathrm{Au}$ on a Si substrate. To do this, a criterion was established, called the null hypothesis, to use in deciding whether to accept or reject the hypothesis. This hypothesis states that there is no difference between two sets of sampled data. In order to minimize any random sampling error before the rejection of the null hypothesis is decided, the probability level is set at low a value $(p=0.05)$. In other words, a null hypothesis is rejected when the probability of observing a difference between the mean data for two different sputtering parameters 
due to a sampling error is less than $5 \%$. Therefore, $p<0.05$ refers to a statistically significant difference [38].

The T-test is the most commonly conducted method in statistical analysis to determine the statistical significance between two sets of sample data by simply comparing their means. T-test is divided into two types: independent and dependent samples T-tests. [38] The independent samples T-test evaluates the difference between sample means, while the dependent samples T-test evaluates the difference between the means of the pre-test and the post-test for the same sample. In this work, the independent samples T-test was used to evaluate the difference between two means of the texture parameters values as a function of the sputter parameters. The general formula for the independent samples T-test is given by the following:

$$
t=\frac{\overline{X_{1}}-\overline{X_{2}}}{S_{\overline{X_{1}}-\overline{X_{2}}}},
$$

where $\overline{X_{1}}$ and $\overline{X_{2}}$ are the means for the first and second samples, respectively, $\mathrm{S}_{\overline{\mathrm{X}_{1}}-\overline{\mathrm{X}_{2}}}$ is the standard error of the difference between the means, and it is given by:

$$
S_{\overline{X_{1}}-\overline{X_{2}}}=\sqrt{S_{\overline{X_{1}}}^{2}+S_{\overline{X_{12}}}{ }^{2}},
$$

where $S_{\overline{X_{1}}}$ is the standard error of the mean for the first sample, and $S_{\overline{X_{2}}}$ is the standard error of the mean for the second sample. Once the t-value is calculated, it must be compared with the critical t-value that is determined by the level of significance (usually $0.05)$ and the degrees of freedom $(d f)$ which equals the summation of the two sample sizes together and subtracting it by $2, d f=n_{1}+n_{2}-2$. The table of the critical t-values can be found in many statistical books. The null hypothesis is rejected when the 
calculated t-value is greater or equal to the critical t-value, thus there is a statistical significant difference between the two sets of sample data [38]. In this work, the T-test was directly calculated, using the Excel software, between every two sets of each texture parameter and for each sputtering parameter. 


\section{EXPERIMENTAL SETUP AND METHOD}

\subsection{Experimental Setup}

\subsubsection{Introduction}

In this chapter, the experimental setup used to sputter thin Au films on Si substrates is discussed along with the methods used to control the deposition parameters and characterize the sputtered Au surfaces. The primary setup includes a DC magnetron sputter deposition system connected to a dry-lab. Gold was sputtered on $\mathrm{Si}$ wafers that were placed inside a sputtering chamber while various deposition parameters were changed. These parameters include the deposition rate, target/substrate distance, orientation, bias, temperature, and gas flow rate. Specific techniques needed to be developed for controlling these deposition parameters. For example, a cooling system was developed to decrease the substrate temperature during the deposition. After the samples were sputtered, they were transferred to the dry-lab and were characterized using an atomic-force microscope (AFM). AFM images were analyzed using the software program Picolmage. 


\subsubsection{Sputtering Machine}

All Au films were deposited using a commercial DC magnetron sputtering system (Corona Vacuum Coaters, Vancouver, BC, Canada) using a circular $5 \mathrm{~cm}$ (2 inch) diameter Au target $(99.99 \%$ pure) located on the door of the sputtering chamber, as shown in Figure 3.1. The door can be opened to allow the Si substrate to be placed on the substrate table inside the chamber. When the door is closed, a turbo pump (V551, Varian), which is connected to the chamber, is used to evacuate the sputtering chamber.

After the system is evacuated to a pressure of approximately $10^{-6}$ torr, the deposition can be started.

(a)

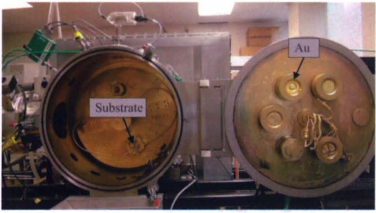

(b)

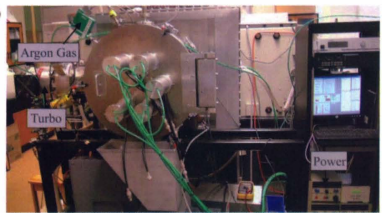

Figure 3.1: The DC sputtering machine (a) Opened, with the inside visible, where the substrate table is; and the Au target is placed on the inner door. (b) Closed, where the turbo pump, argon gas, power supply, and computer are attached to the machine. 


\subsubsection{Dry-Lab}

A dry-lab (HE-553, Vacuum Atmospheres) was used to minimize the Au samples from being contaminated. Figure 3.2 shows the dry-lab, which consists of an antechamber attached to a glovebox in which the deposited samples are placed. The antechamber has two doors: one door can be opened to the ambient air and another can be opened to the glovebox. The deposited samples are transferred in and out of the glovebox using the antechamber. The oxygen and moisture are removed from the dry-lab atmosphere using a filtration system that is housed on the back of the glovebox (not shown).

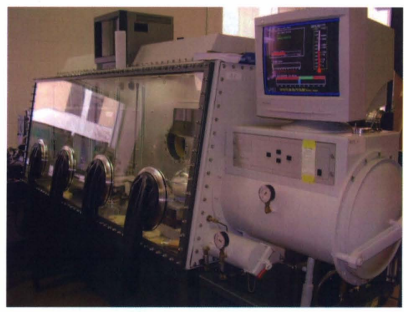

Figure 3.2: The glovebox used in this work. 


\subsection{Experimental Methods}

This section presents the steps used to prepare the substrates and describes the experimental techniques used to control the deposition parameters.

\subsubsection{Cleaning Silicon}

The substrates used in this work were $1 \times 1 \mathrm{~cm}^{2}$ chips cut from lightly-doped p-type (100)-oriented prime grade crystalline Si wafers (International Wafer Service). The cleanliness of the substrate surface prior to the deposition plays a critical role in determining the properties of deposited films because contaminants on the substrate surface can reduce the film adhesion to the substrate and alter the properties of the deposited thin film [39]. Given the importance of cleanliness, a specific procedure was followed to clean the substrate surface before deposition. Piranha solution (3:1 $\mathrm{H}_{2} \mathrm{SO}_{4} / 30 \% \mathrm{H}_{2} \mathrm{O}_{2}$ ) was used to clean the surface by submerging the $\mathrm{Si}$ substrates in the solution for $1 \mathrm{~h}$. This solution is extremely oxidizing and reacts violently with organic compounds; therefore, extreme care was used when handling this solution [40]. Next, the Si substrates were rinsed using Millipore water and dried under a gentle stream of highpurity argon or nitrogen gas. 


\subsubsection{Deposition Parameters}

In this work, Au films were deposited directly onto the $\mathrm{Si}$ wafers without any adhesion layer at a low power of $20 \mathrm{~W}$. Various parameters were changed during the deposition, whereas other parameters were kept constant such as: the target $(\mathrm{Au})$, the substrate $(\mathrm{Si})$, the base pressure $\left(10^{-6}\right.$ torr), and the sputtering power $(20 \mathrm{~W})$. Figure 3.3 shows the schematic diagram illustrating the components used to vary the deposition parameters. These components are the substrate table, copper water-flow cooling block, Peltier cooling device, bias plate, and orientation fixture. Depending on the experiment (and what parameter(s) was(were) changed), the Si substrate can be positioned on either the copper cooling block, the Peltier cooling device, the bias plate, or the sample orientation fixture. The parameters that were varied during deposition are: the deposition rate, target/substrate distance, orientation, bias, temperature, and gas flow rate.

\section{- Deposition Rate and Thickness}

The thickness of the Au films and the sputtering rate were measured using a quartz crystal monitor. The deposition rate used was either the low rate of $0.1 \AA / \mathrm{s}$ or the slightly higher rate of $0.6 \AA /$ s during deposition. It has been reported that [10] small deposition rates lead to large grain sizes. The lowest deposition attainable using the sputter deposition system in our laboratory is $0.1 \AA / \mathrm{s}$. Others in our group have, in the past, used a deposition rate of $0.6 \AA / \mathrm{s}$. Since the obtained morphology for both rates were found to be different in some cases, it was interesting to compare both results and show that a small change in deposition rate can give a significant change in surface features. 


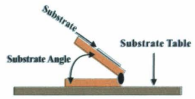

(a)

Au Target

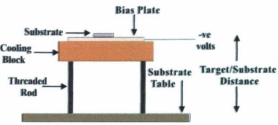

(b)
An Target

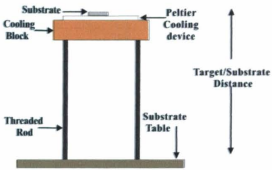

(c)

Figure 3.3: Schematic diagrams illustrating the methods used to vary the: a) substrate orientation, b) substrate bias and/or target/substrate distance, and c) substrate temperature and or target/substrate distance. Diagram not to scale.

\section{- Target to Substrate Distance}

Thin Au films were also deposited at different distances by moving the Si substrate either away from or toward the Au target. The farthest distance the Si substrate was placed from the Au target inside the sputtering machine was $19.7 \mathrm{~cm}$, and the shortest distance was 5 $\mathrm{cm}$. Figure 3.4 shows the cooling block, where samples were mounted, and two rods that 
connect the block to the table. The cooling block was moved precisely back and forth using the threaded rods to change the distance between the Si substrates and the Au target.

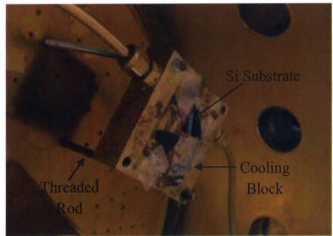

Figure 3.4: The cooling block and the threaded rods that are used to change the target-to-substrate distance.

\section{- Substrate Orientation}

Au films were also deposited on substrates inclined at specific angles using a small custom-built fixture shown in Figure 3.5. The fixture consisted of a sample mount that could be adjusted from $0^{\circ}$ to $180^{\circ}$ with respect to the face of the target. 


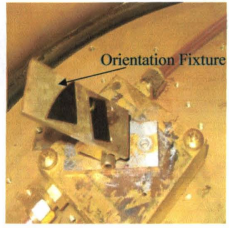

(a)

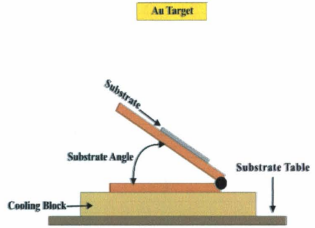

(b)

Figure 3.5: a) Orientation fixture that is placed on top of the cooling block and holds the samples to change their orientations with respect to the target. b) Schematic diagram.

\section{- Substrate Bias}

In some cases, a negative bias was applied to the substrate during the deposition process. To achieve this, the substrate was electrically connected to one of the power supplies of the sputtering system to apply a voltage between -50 and $-350 \mathrm{~V}$. Figure $3.6 \mathrm{a}$ ) shows the plasma that was emitted during the deposition. When the bias was applied, a bright light was observed on the substrate as shown in Figure 3.6b). This indicated that the plasma was also attracted to the substrate as well as the target. 


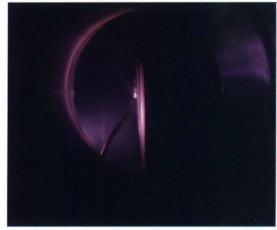

(a)

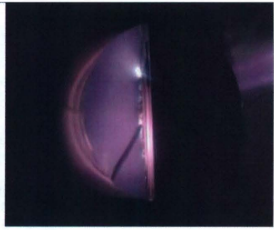

(b)

Figure 3.6: Plasma emitted during deposition (a) with no bias and (b) with bias applied to the substrate.

\section{- Substrate Temperature}

The substrate temperature was controlled using a combination of a copper water-flow cooling block and a Peltier cooling device (Melcor, USA), see Figure 3.7. A Peltier cooling device creates a heat flux between two different materials by passing an electric current through the device. One side of the device is used for heating, and the opposite side for cooling. The greater the difference in temperature, the greater the current necessary to transport heat. To reduce the substrate temperature, the hot side of the Peltier device is attached to the cooling block. The copper cooling block was able to achieve a fixed temperature of $12^{\circ} \mathrm{C}$ during the deposition. This temperature was the standard temperature for most of the sputtering experiments. In some cases, the temperature of the substrate was reduced using the Peltier cooling device, which allowed temperatures from 12 to $-11^{\circ} \mathrm{C}$ to be reached during deposition. 


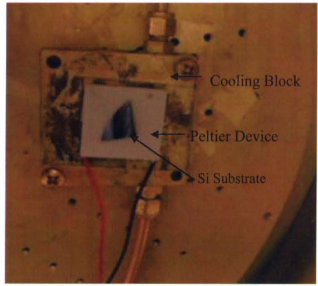

Figure 3.7: A Peltier cooling device is attached to the cooling block to reduce the substrate temperature.

\section{- Gas Flow Rate}

The gas flow rate was set to $50 \mathrm{SCCM}^{(1)}$ during the deposition. However, in a few cases, (see section 4.16) thin Au films were made using a gas flow rate of 10 SCCM.

\subsubsection{AFM Instrumentation}

The sputtered Au films on Si were imaged using contact-mode AFM at room temperature using a PicoSPM, (Agilent technologies, formally Molecular Imaging, USA), shown in Figure 3.8. In all measurements, Si cantilevers (NSC12, MikroMasch, Estonia) with a resonant frequency of approximately $100 \mathrm{kHz}$ were used. All images were acquired at a resolution of $256 \times 256$ pixels with an image size of $1 \times 1 \mu \mathrm{m}^{2}$.

(1) SCCM refers to Standard Cubic Centimeters per Minute. 
The AFM was housed inside a closet lined with acoustic foam on the inner walls to reduce image distortions due to surrounding noise. To further reduce sources of noise, vacuum pumps and other instruments in the laboratory were turned off whenever possible while imaging samples. Samples were imaged at several locations to obtain better statistics.

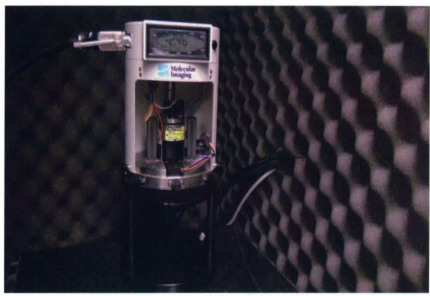

Figure 3.8: A molecular-imaging PicoSPM scanner, seen here with the AFM attachment. 


\section{RESUlTS AND DISCUSSION}

\subsection{Experimental Results and Analysis}

In this chapter, AFM topographs of thin Au films deposited on Si(001) substrates by sputter deposition will be presented. In most cases, three to five samples were produced for each experiment. Each sample was imaged more than ten times at more than three locations, and the best three to six images taken from these samples were analyzed using the texture parameters discussed in section 2.4.2. As a result, the error bars indicate the range of values obtained for each texture parameter for all of the samples deposited under identical conditions.

Although many samples were prepared under various conditions, the general topography of the Au films resembled, unless otherwise stated, that shown in Figure 4.1. As evident in Figures 4.1 a) and b), the $\mathrm{Au}$ film is characterized by a series of hemispherical grains of approximately the same shape and diameter. As will be outlined below, changes in the various deposition parameters mostly resulted in changes in the size of the hemispheres, except in the few cases in which coalescence of the Au film was observed. 

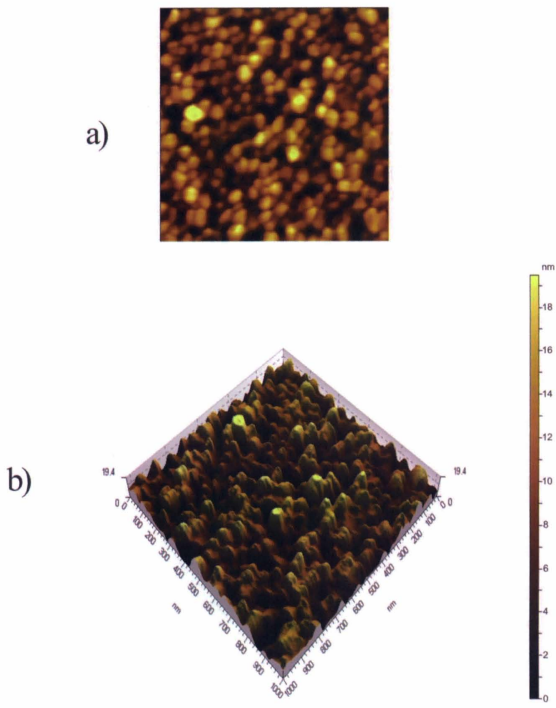

Figure 4.1:a) $1 \times 1 \mathrm{~m}^{2}$ AFM image of $100 \mathrm{~nm}$ thick Au film grown on Si substrate at a deposition rate of $0.1 \AA / s$, orientation of $0^{\circ}$, temperature of $12{ }^{\circ} \mathrm{C}$, bias of $0 \mathrm{~V}$, and target/substrate distance of $19.7 \mathrm{~cm}$. b) Three dimensional representation of the $\mathrm{Au}$ surface. The height scale for the image from black (low) to white (high) is $0-19.4 \mathrm{~nm}$. 


\subsubsection{Grain Size Calculation}

The grain size of the deposited Au films was measured using the Picolmage software, which identifies the location of the grains and calculates the average grain size. Identifying the grains is done in three steps by first converting the surface to a binary image detecting the motifs of a surface, as shown in step 1 of Figure 4.2. The second step involves taking the superposition of the original surface and the result of step 1 to recover only the grains. In the final step 3 , the grains are separated by removing everything below a given threshold height. When the grains on the surface are identified, the average grain size can be calculated directly. It should be noted that this procedure for identifying the grains is an estimations as there does not exist a routing that can identified surface features perfectly. Using a resolution of $256 \times 256$ pixels, the image shown in Figure 4.1 has an average number of pixels per particle of 380 which is sufficient for characterizing the shape of these surface features. 


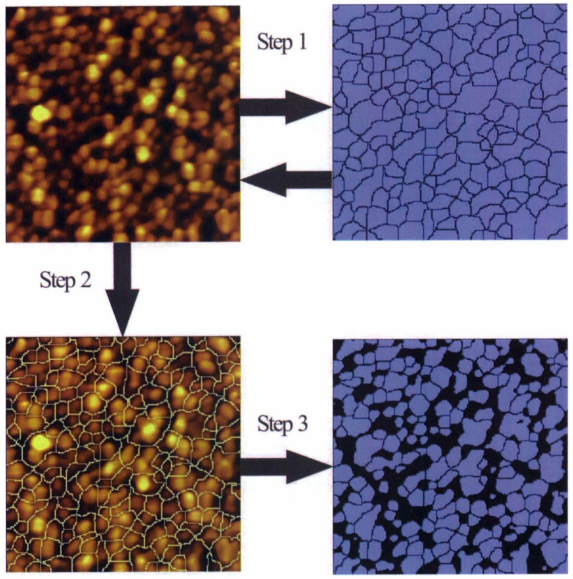

Figure 4.2: The steps used to identify the grains and calculate the average grain size by the Picolmage software: 1) converting the surface to a binary image, 2) taking the superposition of the original surface, and 3) separating the grains. 


\subsubsection{Changing the Target-to-Substrate Distance}

To study the effects of the target/substrate distance on the morphology of the thin Au films, samples were prepared by sputtering $\mathrm{Au}$ at a rate of $0.6 \AA / \mathrm{s}$ at distances of $6.5,8.0$, 14.0 , and $19.7 \mathrm{~cm}$ from the target to the $\mathrm{Si}$ substrates. The results of the analysis of these samples are shown in Figure 4.3. Figures 4.3 a) and b) show that the average grain size and the RMS roughness decrease as the distance between the substrate and the target is increased. Because both of these parameters decrease simultaneously, we can infer that the hemispheres decrease in both diameter and height. The small error bars in Figure 4.3a) indicate the consistency of the grain size between samples. The decrease in the average grain size and RMS roughness caused the surface-to-area ratio to increase slightly with the target/substrate distance, as a result of an increase in the number of smaller grains. However, at a distance of $19.7 \mathrm{~cm}$, the further reduction of the grain size and grain height caused a decrease in the surface-area ratio. The kurtosis, shown in Figure 4.3b), starts at values less than 3 for short target/substrate distances and increases to values greater than 3 when the target/substrate distance increases. These results indicate that the grains at smaller target/substrate distances are broad, as expected of larger-sized grains, and subsequently become narrower as the frequency of the surface features increases, as expected for smaller-sized grains. The skewness shown in Figure $4.3 \mathrm{~b}$ ) is positive at all distances, which indicates that the surface is predominantly composed of peaks; this result is consistent with hemispherical surfaces, as shown in Figure 4.1. The RMS slope follows a similar trend to that of the grain size. At smaller target/substrate distances the grains are larger both in diameter and in height. Therefore, the surface features are expected to give rise to larger slopes, as shown in Figure 4.3b). 
As the grains decrease in diameter and height, the RMS slope also decreases correspondingly. Statistically significant differences (T-test $p<0.05$ ) were found for the values of the average grain size, RMS roughness, RMS slope, skewness, and kurtosis, when the target/substrate distance was changed from $19.7 \mathrm{~cm}$ to $6.5 \mathrm{~cm}$, see Table 4.1 . No significant differences (T-test $p>0.05$ ) for the values of the surface-area ratio were measured when the target/substrate distance was changed from $19.7 \mathrm{~cm}$ to $6.5 \mathrm{~cm}$. 


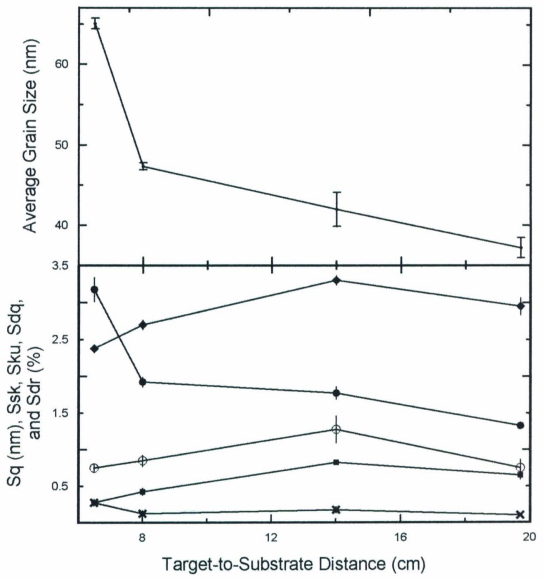

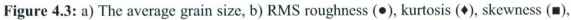
RMS slope $(\mathbf{X})$, and surface-area ratio $(0)$ of the Au films are plotted as a function of target/substrate distance at deposition rate of $0.6 \AA / \mathrm{s}$. Note: The standard deviations for a number of tested samples are indicated by the error bars. 
Table 4.1: T-Test analysis for samples produced using a deposition rate of $0.6 \AA / \mathrm{s}$ while changing the target/substrate distance during deposition.

\begin{tabular}{|c|c|}
\hline $\begin{array}{c}\text { Texture } \\
\text { Parameter }\end{array}$ & T-test Analysis \\
\hline $\begin{array}{l}\text { Average grain } \\
\text { size }\end{array}$ & $\begin{array}{l}\text { SD only between: } \\
6.5 \text { and } 8 \mathrm{~cm} \\
6.5 \text { and } 14 \mathrm{~cm} \\
6.5 \text { and } 19.7 \mathrm{~cm}\end{array}$ \\
\hline RMS roughness & $\begin{array}{l}\text { SD for all values except between: } \\
\qquad 8 \text { and } 14 \mathrm{~cm}\end{array}$ \\
\hline $\begin{array}{l}\text { Surface-area } \\
\text { ratio }\end{array}$ & $\mathrm{ND}(\mathrm{T}$-test $p>0.05)$ \\
\hline Skewness & $\begin{array}{l}\text { SD for all values except between: } \\
\qquad 6.5 \text { and } 8 \mathrm{~cm} \\
14 \text { and } 19.7 \mathrm{~cm}\end{array}$ \\
\hline Kurtosis & $\begin{array}{l}\text { SD for all values except between: } \\
\qquad 8 \text { and } 19.7 \mathrm{~cm} \\
14 \text { and } 19.7 \mathrm{~cm}\end{array}$ \\
\hline RMS Slope & $\begin{array}{l}\text { SD only between: } \\
6.5 \text { and } 19.7 \mathrm{~cm} \\
14 \text { and } 19.7 \mathrm{~cm}\end{array}$ \\
\hline
\end{tabular}

$\mathrm{SD}=$ Statistical Difference, $\mathrm{ND}=$ No Difference. 


\subsubsection{Changing the Substrate Orientation}

To study the effects of the substrate orientation on the morphology of thin Au films, samples were prepared by sputtering $\mathrm{Au}$ at a rate of $0.1 \AA / \mathrm{s}$ and at a target/substrate distance of $19.7 \mathrm{~cm}$ with substrate orientations of $0,30,60$, and $90^{\circ}$. Figures 4.4 a) and b) show that the average grain size decreased and the RMS roughness increased as the substrate orientation was increased. These results imply that the hemispheres decreased in diameter and increased in height as the substrate orientation was increased. This conclusion is also supported by the increase in the surface-area ratio with the increase in substrate angle. The surface area of the sample increases significantly as the average grain size becomes smaller and taller which causes the surface-area ratio to increase. The RMS slope remains constant with the increase in substrate angle. The skewness, as with the previous case, is expected to be greater than zero because of the general shape of the grains on the surface. Because the kurtosis remains fairly constant at a value less than 3, we can also assume that the shapes of the grains are relatively broad. The broadness of the shapes is due to the fact that the overall change in grain size and RMS roughness is relatively small. Although the texture parameters (except the RMS roughness) of the films appear to show a difference when changing the substrate orientations, statistical analysis implied that this difference was not significant (T-test $p>0.05$ ), see Table 4.2. 


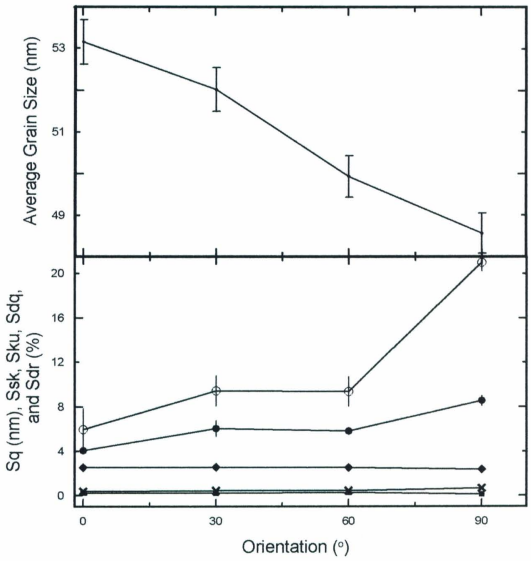

Figure 4.4: a) The average grain size, b) RMS roughness $(\bullet)$, kurtosis $(\bullet)$, surface-area ratio (O), skewness ( $\mathbf{-})$, and RMS slope $(\mathbf{x})$ of the Au films plotted as a function of the substrate orientation with respect to the Au target. Note: The standard deviations for a number of tested samples are indicated by the error bars. 
Table 4.2: T-Test analysis for samples produced at a deposition rate of $0.1 \AA / \mathrm{s}$ while changing the substrate orientation during deposition.

\begin{tabular}{|c|c|}
\hline $\begin{array}{c}\text { Texture } \\
\text { Parameter }\end{array}$ & T-test Analysis \\
\hline $\begin{array}{l}\text { Average grain } \\
\text { size }\end{array}$ & ND (T-test $p>0.05)$ \\
\hline RMS roughness & $\begin{array}{l}\text { SD for all values except between: } \\
\qquad 30 \text { and } 60^{\circ}\end{array}$ \\
\hline $\begin{array}{l}\text { Surface-area } \\
\text { ratio }\end{array}$ & $\begin{array}{l}\text { SD only between: } \\
0 \text { and } 90^{\circ} \\
30 \text { and } 90^{\circ} \\
60 \text { and } 90^{\circ}\end{array}$ \\
\hline Skewness & ND (T-test $p>0.05)$ \\
\hline Kurtosis & ND (T-test $p>0.05$ ) \\
\hline RMS Slope & $\begin{array}{l}\text { SD only between: } \\
0 \text { and } 90^{\circ} \\
30 \text { and } 90^{\circ} \\
60 \text { and } 90^{\circ}\end{array}$ \\
\hline
\end{tabular}

$\mathrm{SD}=$ Statistical Difference, $\mathrm{ND}=$ No Difference. 


\subsubsection{Changing the Substrate Bias}

Next, the effects of the substrate bias on the morphology of thin Au films sputter deposited at 0.1 and $0.6 \AA / \mathrm{s}$ and at target/substrate distances of $5.0,6.5$, and $19.7 \mathrm{~cm}$ were considered. The biases applied to the substrate were $0,-50,-100,-150,-175,-200,-$ 250 , and $-350 \mathrm{~V}$. The samples were imaged and analyzed using the texture parameters shown in section 2.4 .2 and the results of this analysis are shown in Figure 4.5. Figure 4.5 shows that the application of a substrate bias has a small effect on the morphology of the Au films. The data shown in red represent samples prepared using a deposition rate of 0.1 $\AA / \mathrm{s}$ at a sputtering distance of $5 \mathrm{~cm}$. The data shown in blue represent samples prepared using a deposition rate of $0.1 \AA / \mathrm{s}$ at a sputtering distance of $19.7 \mathrm{~cm}$. The data shown in black represent samples prepared using a deposition rate of $0.6 \AA / \mathrm{s}$ at a sputtering distance of $6.5 \mathrm{~cm}$. Lastly, the samples shown in green were prepared using a deposition rate of $0.6 \AA / \mathrm{s}$ at a sputtering distance of $19.7 \mathrm{~cm}$. Figure $4.5 \mathrm{a}$ ) indicates that changes in the target/sample distance decrease the average grain size of the film, as seen in section 4.1.2. This result is supported by the statistical analysis which revealed a significant (Ttest $p<0.05)$ difference between the values of the average grain size when the target/substrate distances were changed, see Table 4.3. However, the application of a negative bias to the substrate reduces the average grain size very little. Thus, there were no significant differences (T-test $p>0.05$ ) between the values of the average grain size when the bias was applied on the substrates. The morphology of the samples prepared using a deposition rate of $0.1 \AA / \mathrm{s}$ at a sputtering distance of $5 \mathrm{~cm}$ were observed to be in the coalescence stage of the Volmer-Weber growth mode, which gave a morphology profile similar to that shown in Figure 4.6. The morphology of the rest of the samples was 
characterized as hemispherical grains as shown in figure 4.1. Figure 4.5 b) shows that the RMS roughness for samples prepared using a deposition rate of $0.1 \AA / \mathrm{s}$ at a sputtering distance of $5 \mathrm{~cm}$ increased slightly with the application of a negatively increasing bias, which indicates that the height of the surface features were increased as the average grain size decreased. The values of the RMS roughness at -200 and $-350 \mathrm{~V}$ were significantly higher than at $0 \mathrm{~V}$. Decreasing grain size and increasing RMS roughness caused the surface-area ratio to first increase in value (at $-50 \mathrm{~V}$ ) and then decrease from -50 to -350 $\mathrm{V}$. The surface-area ratios at -50 to $-350 \mathrm{~V}$ were significantly higher than at $0 \mathrm{~V}$. The samples prepared using a deposition rate of $0.1 \AA / \mathrm{s}$ at a sputtering distance of $19.7 \mathrm{~cm}$ (blue curve) exhibited a slight decrease in RMS roughness and in surface-area ratio with changes in the bias from 0 to $-200 \mathrm{~V}$ followed by an increase from -250 to $-350 \mathrm{~V}$. No significant difference for the values of the RMS roughness were measured when the substrate bias was changed, except, between 0 and $-150,0$ and $-200 \mathrm{~V}$, and -150 and -200 V. No significant difference for the values of the surface-area ratio was measured when the substrate bias was changed. The samples prepared using a deposition rate of $0.6 \AA / \mathrm{s}$ at a sputtering distance of $6.5 \mathrm{~cm}$ (black curve) showed a modest increase in both the RMS roughness and the surface-area ratio. Statistical analysis revealed a significant difference for the values of RMS roughness only when the substrate bias was changed between 0 and $-100 \mathrm{~V}$, and for the values of the surface-area ratio only between 0 and 100 , and 0 and $-200 \mathrm{~V}$. The samples prepared using a deposition rate of $0.6 \AA / \mathrm{s}$ at a sputtering distance of $19.7 \mathrm{~cm}$ (green curve) exhibited a modest decrease in both RMS roughness and surface-area ratio. Statistical analysis revealed a significant difference for the values of RMS roughness and surface are ratio only when the substrate bias was 
changed between 0 and $-100,0$ and -175 , and 0 and $-200 \mathrm{~V}$. For all the samples shown in Figure $4.5 \mathrm{c}$ ), the skewness, and the RMS slope remained approximately constant, which indicates that the general shape of the surface features remained nearly identical. The kurtosis values also remained constant for all the samples, except those prepared using a deposition rate of $0.6 \AA / \mathrm{s}$ at a sputtering distance of $19.7 \mathrm{~cm}$. The kurtosis values of these samples increased to values greater than 3 which implies that the grains have a sharper profile. No significant difference for most of the values of the skewness, kurtosis, and RMS slope were measured when the substrate bias was changed. 


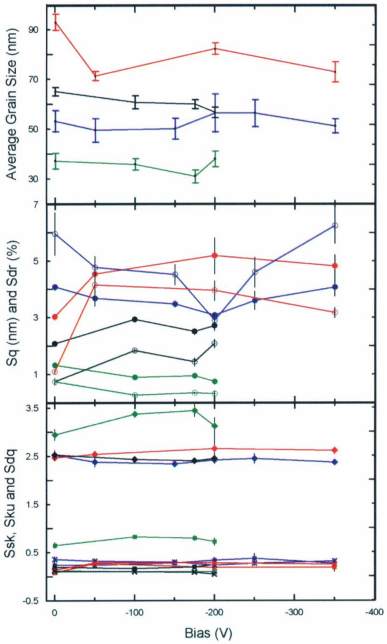

Figure 4.5: a) The average grain size, b) RMS roughness $(\bullet)$, surface-area ratio $(0)$, kurtosis ( $\bullet$ c) skewness ( $\mathbf{m}$ ), and RMS slope ( $\mathbf{x}$ ) of the Au films plotted as a function of the bias. The red curve is at deposition rate of $\mathrm{D}=0.1 \AA / \mathrm{s}$ and target $/$ substrate distance of $\mathrm{d}=5$ $\mathrm{cm}$, the blue curve is at $\mathrm{D}=0.1 \AA / \mathrm{s}$ and $\mathrm{d}=19.7 \mathrm{~cm}$, the black curve is at $\mathrm{D}=0.6 \AA / \mathrm{s}$ and $\mathrm{d}$ $=6.5 \mathrm{~cm}$, and the green curve is at $\mathrm{D}=0.6 \AA / \mathrm{s}$ and $\mathrm{d}=19.7 \mathrm{~cm}$. Note: The standard deviation values for a number of tested samples are indicated by the error bars. 

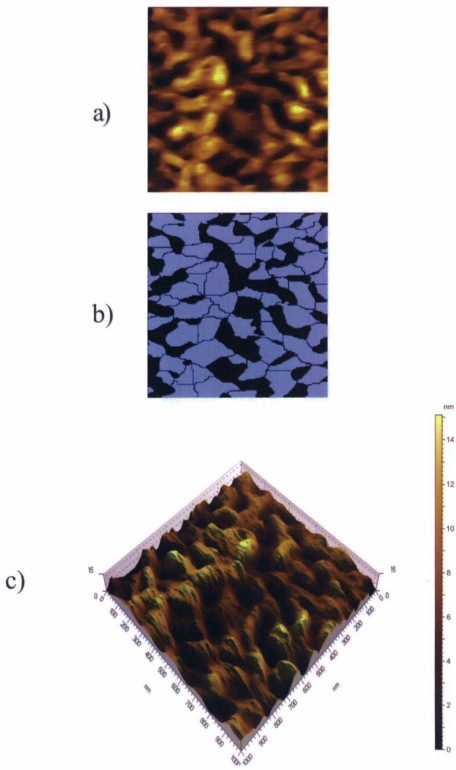

Figure 4.6: a) $1 \times 1 \mathrm{~m}^{2} \mathrm{AFM}$ images of $\mathrm{Au}$ films grown on $\mathrm{Si}$ substrates at deposition rate of $0.1 \AA / \mathrm{s}$, target/substrate distance of $5 \mathrm{~cm}$, and bias of $0 \mathrm{~V}$. b) The binary image after identifying the grains. c) Three dimensional representation of the Au surface. The color contrast scale from black (low) to white (high) is $0-15 \mathrm{~nm}$. 
Table 4.3: T-Test analysis for samples produced at different deposition rates and target/substrate distance, while changing the substrate bias during deposition.

\begin{tabular}{|c|c|c|c|c|}
\hline $\begin{array}{c}\text { Texture } \\
\text { Parameter }\end{array}$ & $\begin{array}{c}\text { For samples } \\
\text { made at } D=0.1 \\
\AA / s, \text { and at } d=5 \\
\mathrm{~cm}\end{array}$ & $\begin{array}{c}\text { For samples } \\
\text { made at } \mathrm{D}=0.1 \\
\AA / \mathrm{s}, \text { and at } \mathrm{d}= \\
19.7 \mathrm{~cm}\end{array}$ & $\begin{array}{c}\text { For samples } \\
\text { made at } \mathrm{D}=0.6 \\
\AA / \mathrm{s}, \text { and at } \mathrm{d}= \\
6.5 \mathrm{~cm}\end{array}$ & $\begin{array}{c}\text { For samples } \\
\text { made at } D=0.6 \\
\AA / s, \text { and at d = } \\
19.7 \mathrm{~cm}\end{array}$ \\
\hline $\begin{array}{l}\text { Average } \\
\text { grain size }\end{array}$ & $\begin{array}{c}\mathrm{ND} \\
(\mathrm{T} \text {-test } p>0.05)\end{array}$ & $\begin{array}{l}\text { SD only between: } \\
-50 \text { and }-350 \mathrm{~V} \\
-50 \text { and }-200 \mathrm{~V}\end{array}$ & $\begin{array}{c}\mathrm{ND} \\
(\mathrm{T} \text {-test } p>0.05)\end{array}$ & $\begin{array}{c}\text { SD only } \\
\text { between: } \\
-100 \text { and } 200 \mathrm{~V}\end{array}$ \\
\hline $\begin{array}{c}\text { RMS } \\
\text { roughness }\end{array}$ & $\begin{array}{l}\text { SD only between: } \\
0 \text { and }-150 \mathrm{~V} \\
0 \text { and }-200 \mathrm{~V} \\
-150 \text { and }-200 \mathrm{~V}\end{array}$ & $\begin{array}{l}\text { SD only between: } \\
0 \text { and }-200 \mathrm{~V} \\
0 \text { and }-300 \mathrm{~V}\end{array}$ & $\begin{array}{l}\text { SD only between: } \\
0 \text { and }-100 \mathrm{~V}\end{array}$ & $\begin{array}{c}\text { SD only } \\
\text { between: } \\
0 \text { and }-100 \mathrm{~V} \\
0 \text { and }-175 \mathrm{~V} \\
0 \text { and }-200 \mathrm{~V}\end{array}$ \\
\hline $\begin{array}{l}\text { Surface- } \\
\text { area ratio }\end{array}$ & $\begin{array}{c}\mathrm{ND} \\
(\mathrm{T} \text {-test } p>0.05)\end{array}$ & $\begin{array}{l}\text { SD only between: } \\
0 \text { and }-50 \mathrm{~V} \\
0 \text { and }-200 \mathrm{~V} \\
0 \text { and }-350 \mathrm{~V}\end{array}$ & $\begin{array}{l}\text { SD only between: } \\
0 \text { and }-100 \mathrm{~V} \\
0 \text { and }-175 \mathrm{~V} \\
0 \text { and }-200 \mathrm{~V}\end{array}$ & $\begin{array}{c}\begin{array}{c}\text { SD only } \\
\text { between: }\end{array} \\
0 \text { and }-100 \mathrm{~V} \\
0 \text { and }-200 \mathrm{~V}\end{array}$ \\
\hline Skewness & $\begin{array}{c}\mathrm{ND} \\
(\mathrm{T} \text {-test } p>0.05)\end{array}$ & $\begin{array}{c}\text { SD only between: } \\
0 \text { and }-50 \mathrm{~V}\end{array}$ & $\begin{array}{c}\text { ND } \\
\text { (T-test } p>0.05)\end{array}$ & $\begin{array}{c}\mathrm{ND} \\
(\mathrm{T} \text {-test } p>0.05)\end{array}$ \\
\hline Kurtosis & $\begin{array}{c}\mathrm{ND} \\
(\mathrm{T} \text {-test } p>0.05)\end{array}$ & $\begin{array}{c}\text { ND } \\
(\text { T-test } p>0.05)\end{array}$ & $\begin{array}{l}\text { SD only between: } \\
0 \text { and }-100 \mathrm{~V}\end{array}$ & $\begin{array}{c}\text { ND } \\
(\text { T-test } p>0.05)\end{array}$ \\
\hline $\begin{array}{l}\text { RMS } \\
\text { Slope }\end{array}$ & $\begin{array}{c}\mathrm{ND} \\
(\mathrm{T}-\mathrm{test} p>0.05)\end{array}$ & $\begin{array}{l}\text { SD only between: } \\
0 \text { and }-50 \mathrm{~V} \\
0 \text { and }-200 \mathrm{~V} \\
0 \text { and }-350 \mathrm{~V}\end{array}$ & $\begin{array}{c}\mathrm{ND} \\
(\mathrm{T}-\text { test } p>0.05)\end{array}$ & $\begin{array}{c}\mathrm{ND} \\
(\mathrm{T} \text {-test } p>0.05)\end{array}$ \\
\hline
\end{tabular}

$\mathrm{SD}=$ Statistical Difference, $\mathrm{ND}=$ No Difference. 


\subsubsection{Changing the Substrate Temperature}

To study the effects of temperature on the morphology of thin Au films, samples were prepared by sputtering $\mathrm{Au}$ at a rate of 0.1 and $0.6 \AA / \mathrm{s}$ at target/substrate distances of 5 and $19.7 \mathrm{~cm}$ and at deposition temperatures of $-11,-8,-6,0,5,6$, and $12{ }^{\circ} \mathrm{C}$. The samples were analyzed using the texture parameters described in section 2.4 .2 and the results of this analysis are shown in Figure 4.7. The data shown in red represent samples prepared using a deposition rate of $0.1 \AA / \mathrm{s}$ at a sputtering distance of $5 \mathrm{~cm}$. The data shown in blue represent samples prepared using a deposition rate of $0.1 \AA / \mathrm{s}$ at a sputtering distance of $19.7 \mathrm{~cm}$. Lastly, the samples shown in green were prepared using a deposition rate of 0.6 $\AA / \mathrm{s}$ at a sputtering distance of $19.7 \mathrm{~cm}$. Figure $4.7 \mathrm{a}$ ) indicates that the samples prepared using a deposition rate of $0.1 \AA / \mathrm{s}$ at a sputtering distance of $5 \mathrm{~cm}$ showed a significant increase in grain size with an increase in temperature, except between 0 and $5{ }^{\circ} \mathrm{C}$, as no statistical differences were measured, see Table 4.4 . These samples were observed to be at the coalescence stage of the Volmer-Weber growth stage and exhibited a morphology profile similar to that shown in Figure 4.6. The average RMS roughness of these samples decreased slightly with increasing temperature, which indicates that the height of the surface features decreased as the average grain sizes increased. The result of increased grain sizes and decreasing RMS roughness values caused, as expected, a decrease in the surface-area ratio. Statistical analysis showed that there were only significant differences for the values of the RMS roughness and the surface-area ratio when the temperature was changed from -8 to $12^{\circ} \mathrm{C}$. Because the kurtosis remained approximately constant at a value less than 3 , we can also conclude that the grains are relatively broad in shape. No significant difference was measured for the values of the kurtosis except when the 
temperature was changed from 5 to $12^{\circ} \mathrm{C}$. The samples prepared using a deposition rate of $0.1 \AA / \mathrm{s}$ at a sputtering distance of $19.7 \mathrm{~cm}$ showed an almost negligible change and no significant difference in average grain size as the temperature was changed. The morphology of these samples was similar to that shown in Figure 4.1. The RMS slope of these samples also remained approximately constant as the temperature was changed; however, the small changes in grain size and RMS roughness compounded to produce a dip in the surface-area ratio at $0^{\circ} \mathrm{C}$. No significant difference was measured for the values of the RMS roughness except when the temperature was changed between 0 and $12{ }^{\circ} \mathrm{C}$, and no significant differences were measured as well for the values of the RMS slope and surface-area ratio. The samples prepared using a deposition rate of $0.6 \AA / \mathrm{s}$ at a sputtering distance of $19.7 \mathrm{~cm}$ showed a modest increase in grain size with increasing temperature. As with the previous case, the morphology of these samples was also similar to that shown in Figure 4.1. Significant differences were obtained for the values of the average grain size when the temperature was changed between $6{ }^{\circ} \mathrm{C}$ and the rest of the temperatures, and between 0 and $12^{\circ} \mathrm{C}$. Whereas the grain size increased slightly, the RMS roughness decreased, which caused the surface-area ratio to decrease slightly. Significant differences were obtained for the values of RMS roughness when the temperature was changed between -11 and $12{ }^{\circ} \mathrm{C},-6$ and $0{ }^{\circ} \mathrm{C}$, and -6 and $12^{\circ} \mathrm{C}$. The kurtosis increased to values greater than 3 for all the samples made using a target/substrate distance greater than $19.7 \mathrm{~cm}$, as seen in section 4.1 .2 . This result indicates that the grains became narrower as the frequency of the surface features increased, which is expected for smaller-sized grains. Significant differences were obtained for the values of RMS roughness when the temperature was changed between - 
11 and $6{ }^{\circ} \mathrm{C},-11$ and $12{ }^{\circ} \mathrm{C},-6$ and $0{ }^{\circ} \mathrm{C},-6$ and $12{ }^{\circ} \mathrm{C}$, and 0 and $12{ }^{\circ} \mathrm{C}$. For all the samples shown in Figure 4.7, the skewness and the RMS slope remained approximately constant, which indicates that the general shape of the surface features remained approximately the same. 


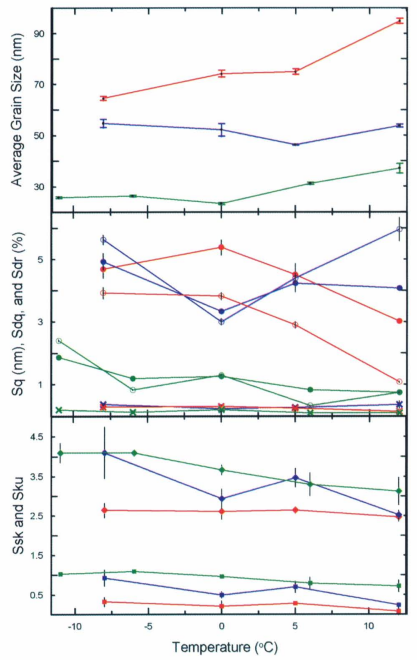

Figure 4.7: a) The average grain size, b) RMS roughness $(\bullet)$, surface-area ratio $(0)$, RMS slope ( $\mathbf{x}$ ), c) skewness ( $\mathbf{m}$ ), and kurtosis ( $\bullet$ ) of the Au films plotted as a function of the temperature. The red curve is at deposition rate of $\mathrm{D}=0.1 \AA / \mathrm{s}$ and target/substrate distance of $\mathrm{d}=5 \mathrm{~cm}$, the blue curve is at $\mathrm{D}=0.1 \AA / \mathrm{s}$ and $\mathrm{d}=19.7 \mathrm{~cm}$, and the green curve is at $\mathrm{D}=0.6 \AA / \mathrm{s}$ and $\mathrm{d}=19.7 \mathrm{~cm}$. Note: The standard deviation values for a number of tested samples are indicated by the error bars. 
Table 4.4: T-Test analysis for samples produced at different deposition rates and target/substrate distances while changing the substrate temperature during deposition.

\begin{tabular}{|c|c|c|c|}
\hline $\begin{array}{c}\text { Texture } \\
\text { Parameter }\end{array}$ & $\begin{array}{c}\text { For samples } \\
\text { made at } \mathrm{D}=0.1 \\
\AA / \mathrm{s} \text { and at } \mathrm{d}= \\
19.7 \mathrm{~cm}\end{array}$ & $\begin{array}{c}\text { For samples made at } \\
\begin{array}{c}\mathrm{D}=0.1 \AA / \mathrm{s} \text {, and at } \mathrm{d} \\
=5 \mathrm{~cm}\end{array}\end{array}$ & $\begin{array}{c}\text { For samples made at } \\
D=0.6 \AA / \mathrm{s} \text {, and } d= \\
19.7 \mathrm{~cm}\end{array}$ \\
\hline $\begin{array}{l}\text { Average } \\
\text { grain size }\end{array}$ & $\begin{array}{c}\text { ND } \\
(\text { T-test } p>0.05)\end{array}$ & $\begin{array}{l}\text { SD for all values } \\
\text { except between: } \\
0 \text { and } 5^{\circ} \mathrm{C}\end{array}$ & $\begin{array}{l}\text { SD only between: } \\
6 \text { and }-11^{\circ} \mathrm{C} \\
6 \text { and }-6^{\circ} \mathrm{C} \\
6 \text { and } 0^{\circ} \mathrm{C} \\
6 \text { and } 12^{\circ} \mathrm{C} \\
0 \text { and } 12^{\circ} \mathrm{C}\end{array}$ \\
\hline $\begin{array}{c}\text { RMS } \\
\text { roughness }\end{array}$ & $\begin{array}{l}\text { SD only between: } \\
0 \text { and } 12^{\circ} \mathrm{C}\end{array}$ & $\begin{array}{l}\text { SD only between: } \\
-8 \text { and } 12^{\circ} \mathrm{C} \\
0 \text { and } 12^{\circ} \mathrm{C}\end{array}$ & $\begin{array}{l}\text { SD for all values } \\
\text { except between: } \\
-11 \text { and } 12^{\circ} \mathrm{C} \\
-6 \text { and } 0^{\circ} \mathrm{C} \\
-6 \text { and } 12^{\circ} \mathrm{C}\end{array}$ \\
\hline $\begin{array}{l}\text { Surface- } \\
\text { area ratio }\end{array}$ & $\begin{array}{c}\mathrm{ND} \\
(\mathrm{T}-\mathrm{test} p>0.05)\end{array}$ & $\begin{array}{l}\text { SD only between: } \\
-8 \text { and } 12^{\circ} \mathrm{C} \\
0 \text { and } 12^{\circ} \mathrm{C} \\
5 \text { and } 12{ }^{\circ} \mathrm{C}\end{array}$ & $\begin{array}{l}\text { SD only between: } \\
-11 \text { and }-6^{\circ} \mathrm{C} \\
-11 \text { and } 0^{\circ} \mathrm{C} \\
-11 \text { and } 6^{\circ} \mathrm{C} \\
-11 \text { and } 12^{\circ} \mathrm{C} \\
0 \text { and } 12^{\circ} \mathrm{C} \\
0 \text { and } 6^{\circ} \mathrm{C}\end{array}$ \\
\hline Skewness & $\begin{array}{l}\text { SD only between: } \\
-8 \text { and } 12^{\circ} \mathrm{C} \\
0 \text { and } 12^{\circ} \mathrm{C} \\
5 \text { and } 12^{\circ} \mathrm{C}\end{array}$ & $\begin{array}{l}\text { SD only between: } \\
-8 \text { and } 12^{\circ} \mathrm{C} \\
0 \text { and } 12^{\circ} \mathrm{C} \\
5 \text { and } 12^{\circ} \mathrm{C}\end{array}$ & $\begin{array}{l}\text { SD only between: } \\
-11 \text { and } 12^{\circ} \mathrm{C} \\
-6 \text { and } 12^{\circ} \mathrm{C} \\
0 \text { and } 12^{\circ} \mathrm{C} \\
6 \text { and } 12^{\circ} \mathrm{C}\end{array}$ \\
\hline
\end{tabular}




\begin{tabular}{|c|c|c|c|}
\hline Kurtosis & $\begin{array}{c}\text { SD only between: } \\
5 \text { and } 12^{\circ} \mathrm{C}\end{array}$ & $\begin{array}{l}\text { SD only between: } \\
5 \text { and } 12^{\circ} \mathrm{C}\end{array}$ & $\begin{array}{l}\text { SD only between: } \\
-11 \text { and } 6^{\circ} \mathrm{C} \\
-11 \text { and } 12{ }^{\circ} \mathrm{C} \\
-6 \text { and } 0{ }^{\circ} \mathrm{C} \\
-6 \text { and } 12^{\circ} \mathrm{C} \\
0 \text { and } 12{ }^{\circ} \mathrm{C}\end{array}$ \\
\hline $\begin{array}{l}\text { RMS } \\
\text { Slope }\end{array}$ & $\begin{array}{c}\mathrm{ND} \\
(\mathrm{T} \text {-test } p>0.05)\end{array}$ & $\begin{array}{l}\text { SD only between: } \\
-8 \text { and } 12{ }^{\circ} \mathrm{C} \\
0 \text { and } 12^{\circ} \mathrm{C}\end{array}$ & $\begin{array}{l}\text { SD only between: } \\
-11 \text { and } 6^{\circ} \mathrm{C} \\
-11 \text { and } 12^{\circ} \mathrm{C} \\
0 \text { and } 6^{\circ} \mathrm{C} \\
0 \text { and } 12^{\circ} \mathrm{C}\end{array}$ \\
\hline
\end{tabular}

$\mathrm{SD}=$ Statistical Difference, $\mathrm{ND}=$ No Difference.

\subsubsection{Changing the Gas Flow Rate}

The samples discussed in sections 4,1.2 to 4.1.5 were deposited using a gas flow rate of 50 SCCM. Samples were synthesized using a gas flow rate of 10 SCCM with a target/sample distance of $5 \mathrm{~cm}$ with zero bias and at a temperature of $12{ }^{\circ} \mathrm{C}$. The morphology of the Au film changed significantly when a gas flow rate of 10 SCCM was used, as shown in Figure 4.8, compared to a sample synthesized under similar conditions using a gas flow rate of $50 \mathrm{SCCM}$ as shown in Figure 4.6. The sample shown in Figure 4.8 is displayed with a height scale from black to white of $0-102 \mathrm{~nm}$ compared to the sample shown in Figure 4.6 displayed with a much smaller height scale from $0-15 \mathrm{~nm}$. Based on the two images shown in Figures 4.6 and 4.8, the sample synthesized at a lower gas flow rate exhibits significantly larger surface features compared to the sample 
synthesized with the higher gas flow rate. It appears also that Au surfaces can no longer be identified as grains even though the Picolmage software calculated an average grain size. The roughness analysis of the samples prepared with the two different values of gas flow rate is shown in Table 4.5 and clearly reflects the increase in roughness of the samples prepared with a low gas flow rate.

Table 4.5: Analysis of samples synthesized under identical conditions with the exception of different flow rates.

\begin{tabular}{|c|c|c|c|c|c|c|}
\hline $\begin{array}{c}\text { Gas Flow } \\
\text { Rate }\end{array}$ & $\begin{array}{c}\text { Average } \\
\text { Grain Size } \\
(\mathbf{n m})\end{array}$ & $\begin{array}{c}\text { RMS } \\
\text { Roughness } \\
(\mathbf{n m})\end{array}$ & Skewness & Kurtosis & $\begin{array}{c}\text { Surface- } \\
\text { Area } \\
\text { Ratio } \\
\mathbf{( \% )}\end{array}$ & $\begin{array}{c}\text { RMS } \\
\text { Slope } \\
(\mathbf{n m})\end{array}$ \\
\hline 10 SCCM & $180 \pm 10$ & $21 \pm 5$ & $-0.1 \pm 0.2$ & $2.6 \pm 0.2$ & $12 \pm 5$ & $0.5 \pm 0.1$ \\
\hline 50 SCCM & $93 \pm 6$ & $3 \pm 0.2$ & $0.1 \pm 0.1$ & $2.5 \pm 0.1$ & $1.1 \pm 0.2$ & $0.1 \pm 0$ \\
\hline T-Test & SD & SD & ND & ND & SD & SD \\
\hline
\end{tabular}

$\mathrm{SD}=$ Statistical Difference, $\mathrm{ND}=$ No Difference. 
a)
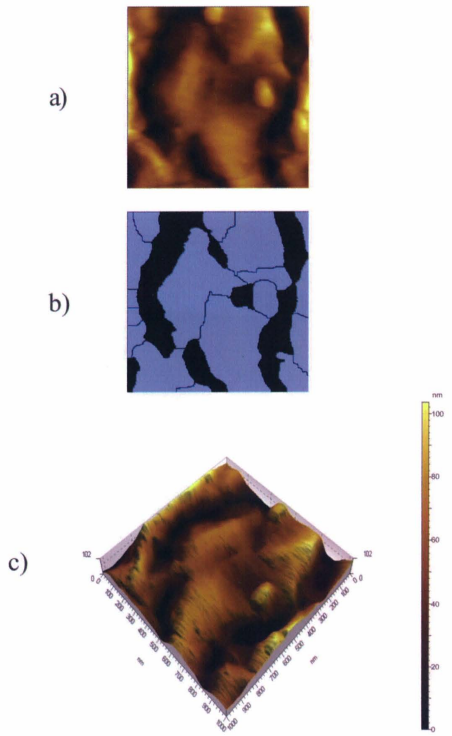

Figure 4.8: a) $1 \times 1 \mu \mathrm{m}^{2}$ AFM images of Au films grown on Si substrates at deposition rate of $0.1 \AA / \mathrm{s}$, target to substrate distance of $5 \mathrm{~cm}$, bias of $0 \mathrm{~V}$, and gas flow rate of 10 SCCM. b) The binary image after identifying the grains. c) Three dimensional representation of the Au surface. The color contrast scale from black (low) to white (high) is 0-102 nm. 


\subsection{Discussion}

It was mentioned in section 2.3.1 that the generation of different morphologies is governed by the surface energy of thin films through equation 2.2 . The $\mathrm{Si}(001)$ substrates used in this work have a native oxide as the exposed surface. Since the surface energy of $\mathrm{Au}(111)^{(2)}$ of about [41] $\gamma_{A u}=1.5 \mathrm{~J} / \mathrm{m}^{2}$ which is higher than the surface energy of $\mathrm{SiO}_{2}$ of about $\gamma_{\mathrm{SiO}_{2}}=0.28 \mathrm{~J} / \mathrm{m}^{2}$, Volmer-Weber (VW) should be the expected growth mode for the formation of thin $\mathrm{Au}$ films on $\mathrm{Si}(001)$ substrates. The analysis of the samples prepared in this work suggests that the formation of thin $\mathrm{Au}$ films on $\mathrm{Si}(001)$ substrates is consistent with the VW structure mode. In this type of growth mode, the deposited atoms have a higher affinity for each other than for the substrate, which initially results, in the nucleation of discrete islands on the substrate. This structure mode is consistent with the observed results of the samples prepared at distances greater than $5 \mathrm{~cm}$ exhibiting semispherical surface features. The next stage in the VW growth mode, known as coalescence, occurs when neighboring semi-spherical grains come together to form elongated island-shaped grains, as was observed for samples deposited at a rate of $0.1 \AA / \mathrm{s}$ at a target/substrate distance of $5 \mathrm{~cm}$. [42]

The hemispherical shape of the grains observed in the Au films is similar to those observed by others [7, 10,43, 44]. For instance, Mertens et al. obtained granular surfaces for 20 and $80 \mathrm{~nm}$ thick Au films deposited on $\mathrm{Si}$ by thermal evaporation at rates of 0.2 and $0.02 \AA / s$, respectively. The main difference between these films and ours was the size of the hemispherical grains. For example, the average grain size of the $20 \mathrm{~nm}$ thick Au

\footnotetext{
(2) Although we did not perform any X-ray diffraction measurements to confirm that the Au surfaces produced in this work were oriented in the (111) direction, unpublished work done previously has shown sputtered Au films to be predominately orientated in the (111) direction.
} 
films ranged from 30 to $35 \mathrm{~nm}$ with an RMS roughness of $1.7 \mathrm{~nm}$ [10], which is similar to our results obtained when the substrate bias and temperature were varied at a deposition rate of $0.6 \AA / \mathrm{s}$ and target/substrate distance of $19.7 \mathrm{~cm}$. The average grain size of the $80 \mathrm{~nm}$ thick Au films (which is closer to our film thickness) was approximately 60 $\mathrm{nm}$ with an RMS roughness $1.6 \mathrm{~nm}$ [10]. These results are also consistent with our observations.

\subsubsection{Changing the Target-to-Substrate Distance}

The target-to-substrate distance has been discussed rarely in the literature. Sun et al. positioned their $\mathrm{Si}$ substrates $6 \mathrm{~cm}$ from the sputtering target [23], whereas Golan et al. placed their Si substrates $23 \mathrm{~cm}$ above the target [18]. In many other cases, the target-tosubstrate distance was not mentioned $[10,22,44]$. In this work, changes in the target/substrate distance significantly influenced the surface morphology of the Au films: the greater the distance between the target and the substrate, the smaller the grain size. Specifically, average grain sizes of $65 \pm 3$ and $37 \pm 6 \mathrm{~nm}$ were observed when the target/substrate distance was set to 6.5 and $19.7 \mathrm{~cm}$, respectively, with a deposition rate was $0.6 \AA / \mathrm{s}$. These grain sizes are approximately $20 \%$ larger than those reported by Sun et al., who found an average grain size of $54.3 \mathrm{~nm}$ at a target/substrate distance of $6 \mathrm{~cm}$, and by Golan et al., who obtained an average grain size of $25 \mathrm{~nm}$ at a target/substrate distance of $23 \mathrm{~cm}$. The difference in average grain size may be due to the deposition rate. In this work, a reduction in the deposition rate from 0.6 to $0.1 \AA /$ s caused the average grain size to increase from 37.2 to $53.2 \mathrm{~nm}$. This result agrees with those of Mertens et 
al., who observed a decrease in the average grain size with an increase in deposition rate [10]. The previously cited results from Golan et al. were obtained at a higher deposition rate of $1 \AA / \mathrm{s}$, which could easily account for the $20 \%$ difference. Unfortunately, the deposition rate used by Sun et al. was not specified.

\subsubsection{Changing the Substrate Orientation}

Investigations of the effects of changing the substrate orientation was inspired by the work of Kawasaki [45], who obtained unique results in the literature for the growth of Au films on mica by simple DC glow discharge sputtering. In this work layer-by-layer growth was observed when Au films were deposited on mica by placement of the substrate in a vertical configuration $3 \mathrm{~cm}$ away from the edge of a Au target being held horizontally. Although mica is clearly a significantly different substrate than $\mathrm{Si}$, it was of interest to see if the sample orientation had any effect on the surface morphology. Therefore, Si substrates were placed at different orientations with respect to the Au target to investigate the effect of the substrate orientation on the surface morphology. Unfortunately, changes in the substrate orientation exhibited no significant influence on the surface morphology of the Au films sputtered onto Si.

\subsubsection{Changing the Substrate Bias}

When a negative bias is applied to the substrate during the sputter deposition process, argon ions become attracted to the substrate and therefore move toward it. The film 
surface becomes activated and gives sufficient energy to the surface $\mathrm{Au}$ adatoms to enhance interlayer mass transport, which involves the adatoms moving from higher regions to lower regions [45]. However, according to Chun, this process has little effect on thin films thicker than $10 \mathrm{~nm}$ [46]. The Au films synthesized in this work consistently remained in the VW growth mode irrespective of the application of a substrate bias. However, the applied voltage did have a small effect in reducing the average grain size which is consistent with the results obtained by Chun [46].

\subsubsection{Changing the Substrate Temperature}

A reduction of the substrate temperature reduces the diffusion coefficient of the Au adatoms as they are deposited onto the substrate [47]. Therefore, a reduction of the substrate temperature during the deposition process would be expected to lead to a more uniform thin film with fewer surface features. From the results observed in this work, the reduction of the substrate temperature during the deposition process reduced the average grain size, which indicates that the Au adatoms travel shorter distances after they make contact with the substrate. Substrate cooling had the largest effect when the target/substrate distance was $5 \mathrm{~cm}$ and the deposition rate was $0.1 \AA / \mathrm{s}$. No effect was observed when the target/substrate distance was increased and the deposition rate was kept low at $0.6 \AA / \mathrm{s}$. We hypothesize that in the first two cases, cooling the substrate reduced the kinetic energy of the Au adatoms, thereby reducing their ability to diffuse along the sample surface. In the case in which the target/substrate distance was increased but the deposition rate was kept low, it is believed that the kinetic energy of the Au atoms 
was already low when they reached the substrate, therefore reducing the effect of substrate cooling.

The previously discussed results are consistent with the effects of performing $\mathrm{Au}$ deposition at elevated temperatures or performing post deposition annealing [18-22, 24]. In these cases, an increase in the temperature increased the mobility of the Au adatoms, which allowed the adatoms to move greater distances along the surface. This increased transport distance led to an increase in the average grain size. For instance, Golan et al. observed an increase in grain size from 30 to $45 \mathrm{~nm}$ for thin Au films sputtered on $\mathrm{Si}$, and from 25 to $120 \mathrm{~nm}$ for thin Au films evaporated on Si after annealing the samples at 250 ${ }^{\circ} \mathrm{C}$ [18]. Similarly, Santos et al. studied the surface evolution of annealed Au thin films deposited on $\mathrm{SiO}_{2}$ substrates using thermal evaporation. Their results showed that as the annealing temperature was increased from 300 to $900{ }^{\circ} \mathrm{C}$, the mean grain size increased from 25 to $88 \mathrm{~nm}$ and the RMS roughness increased from 8.3 to $56.5 \mathrm{~nm}$ [21].

\subsubsection{Changing the Substrate Gas Flow Rate}

The sputtering gas flow had the reverse effect to the sample temperature. A reduction of the sputtering gas flow decreased the number of collisions the Au adatoms encountered when travelling from the target to the substrate. This resulted in an increase in the kinetic energy and the impinging rate of the deposited Au atoms. A change in the gas flow rate from $50 \mathrm{SCCM}$ to $10 \mathrm{SCCM}$ resulted in an increase in the average grain size and in the surface roughness, as predicted. These results are in agreement with those of Chan et al., 
who observed a reduction in the deposition gas flow (sputtering pressure) resulted in rougher films when $\mathrm{Cu}$ was sputter coated onto $\mathrm{Si} \mathrm{[48].}$ 


\section{Conclusion}

\subsection{Summary of the Work}

A study has been conducted on the effects of deposition rate, target/substrate distance, substrate orientation, substrate bias, substrate temperature, and gas flow rate on the morphology of thin Au films deposited on $\mathrm{Si}(001)$ substrates by DC magnetron sputter deposition. The data collected in this work suggest that the deposition of Au on Si follows the typical Volmer-Weber growth mode. The morphology of the Au films in most cases was characterized as hemispherical grains dispersed uniformly on the surface. In some cases, the coalescence stage was observed as the hemispherical grains joined together forming elongated grains on the surface. The deposition rate, target/substrate distance, and gas flow most strongly affected the Au morphology. In particular, by increasing the sputtering rate, target/substrate distance, and gas flow rate smaller $\mathrm{Au}$ grains were produced. These observations were consistent with those reported by others $[10,48]$. Cooling, applying a bias, and/or changing the orientation of the substrate during the deposition caused only small changes (if any) to the surface morphology. As shown in Table 5.1 , by varying the deposition parameters it is possible to obtain a wide range of grain morphology which can be tailored for a given application. 
Table 5.1: Changing the various deposition parameters allows a wide range of average grain size and RMS roughness to be achieved.

\begin{tabular}{|c|c|c|c|c|}
\hline Variable & Range & $\begin{array}{c}\text { Average Grain } \\
\text { Size }\end{array}$ & $\begin{array}{c}\text { RMS } \\
\text { Roughness }\end{array}$ & Comments \\
\hline $\begin{array}{c}\text { Target/Substrate } \\
\text { Distance }\end{array}$ & $\begin{array}{l}6.5 \text { to } \\
19.6 \mathrm{~cm}\end{array}$ & $\begin{array}{l}65 \pm 3 \text { to } \\
37 \pm 6 \mathrm{~nm}\end{array}$ & $\begin{array}{l}3.2 \pm 0.3 \text { to } \\
1.3 \pm 0.1 \mathrm{~nm}\end{array}$ & $\begin{array}{l}\text { Deposition rate } \\
\quad=0.6 \AA / \mathrm{s}\end{array}$ \\
\hline $\begin{array}{l}\text { Substrate } \\
\text { Orientation }\end{array}$ & 0 to $90^{\circ}$ & $\begin{array}{c}50 \pm 8 \text { to } \\
55 \pm 11 \mathrm{~nm}\end{array}$ & $\begin{array}{l}4 \pm 0.2 \text { to } \\
9 \pm 1 \mathrm{~nm}\end{array}$ & $\begin{array}{l}\text { Deposition rate } \\
\quad=0.1 \AA / \mathrm{s}\end{array}$ \\
\hline Substrate Bias & $\begin{array}{l}0 \text { to - } \\
350 \mathrm{~V}\end{array}$ & $\begin{array}{l}93 \pm 6 \text { to } \\
73 \pm 8 \mathrm{~nm} \\
53 \pm 8.5 \text { to } \\
51 \pm 6 \mathrm{~nm} \\
65 \pm 3 \text { to } \\
57 \pm 4 \mathrm{~nm} \\
37 \pm 6 \text { to } \\
38 \pm 6 \mathrm{~nm}\end{array}$ & $\begin{array}{l}3 \pm 0.2 \text { to } \\
5 \pm 0.8 \mathrm{~nm} \\
4 \pm 0.2 \text { to } \\
4 \pm 0.7 \mathrm{~nm} \\
2 \pm 0.1 \text { to } \\
3 \pm 0.3 \mathrm{~nm} \\
1 \pm 0.1 \text { to } \\
0.8 \pm 0.1 \mathrm{~nm}\end{array}$ & $\begin{array}{l}\text { Varying the } \\
\text { target/substrate } \\
\text { distance and } \\
\text { deposition rate }\end{array}$ \\
\hline $\begin{array}{l}\text { Substrate } \\
\text { Temperature }\end{array}$ & $\begin{array}{l}12 \text { to - } \\
11^{\circ} \mathrm{C}\end{array}$ & $\begin{array}{l}95 \pm 5 \text { to } \\
64 \pm 4 \mathrm{~nm} \\
54 \pm 3 \text { to } \\
55 \pm 8 \mathrm{~nm} \\
37 \pm 6 \text { to } \\
26 \pm 1 \mathrm{~nm}\end{array}$ & $\begin{array}{l}3 \pm 0.2 \text { to } \\
5 \pm 0.9 \mathrm{~nm} \\
4 \pm 0.2 \text { to } \\
5 \pm 0.9 \mathrm{~nm} \\
0.8 \pm 0.1 \text { to } \\
2 \pm 0.1 \mathrm{~nm}\end{array}$ & $\begin{array}{l}\text { Varying the } \\
\text { target/substrate } \\
\text { distance and } \\
\text { deposition rate }\end{array}$ \\
\hline $\begin{array}{l}\text { Substrate Gas } \\
\text { Flow Rate }\end{array}$ & $\begin{array}{l}10 \text { to } 50 \\
\mathrm{SCCM}\end{array}$ & $\begin{array}{l}180 \pm 10 \text { to } \\
93 \pm 6 \mathrm{~nm}\end{array}$ & $\begin{array}{l}21 \pm 5 \text { to } \\
3 \pm 0.2 \mathrm{~nm}\end{array}$ & $\begin{array}{l}\text { Deposition rate } \\
\quad=0.1 \AA / \mathrm{s}\end{array}$ \\
\hline
\end{tabular}


One clear result of this work is that the RMS value, by itself, is insufficient for characterizing the roughness of surfaces. Although the RMS roughness gives an excellent indication on the distribution of the surface heights, it gives no any indication of the average grain size. This is obvious from Table 5.1 that changing the deposition parameters can have an effect on the morphology of Au film and can change the average grain size, but still has similar values of RMS roughness. For this reason, it is imperative when characterizing the morphology of surfaces to include other texture parameters. At the very least including the average grain size with the RMS roughness provides information both the average vertical and the horizontal length scales associated with the sample surface.

\subsection{Future Work}

Additional experiments, such as changing the value of the gas flow rate during deposition, should be conducted to expand on the results obtained in this work. Also, flame annealing the samples after deposition has been shown to produce atomically flat Au films on mica. It would be interested to see what the effect of hydrogen flame annealing of $\mathrm{Au}$ films on Si substrates.

In the introduction of this text, it was discussed how the influence of the roughness of thin Au films on the sensitivity of cantilever sensors is still unknown. It was hypothesized that this is possibly due to the lack of consistency between different experiments [2, 5-10]. Since it is now possible to deposit Au with a wide range of morphologies, it would be beneficial to attempt to understand the effect of these different 
Au morphologies on the sensitivity of cantilever sensors by a specific experimental plan. This can be done by performing a series of systematic experiments and testing all the deposited Au films in this work with at least two different reaction mechanisms. Once done, the influence of the Au film morphology on the cantilever sensitivity can hopefully be positively determined. This will lead to understanding the affect of Au films on the microcatilver sensors and in detecting more molecules in a given environment. Although this work seems to have narrow applications, the wide range of average grain size and RMS roughness that were obtained for depositing Au films on $\mathrm{Si}(001)$ with changing the deposition parameters can be helpful for researchers to choose the desired morphology for different future applications. 


\section{Bibliography}

[1] H.F. Ji, Y.F. Zhang, V.V. Purushotham, S. Kondu, B. Ramachandran, T. Thundat, D.T. Haynie, 1,6-Hexanedithiol monolayer as a receptor for specific recognition of alkylmercury, Analyst 130 (2005) 1577-1579.

[2] M. Godin, P.J. Williams, V. Tabard-Cossa, O. Laroche, L.Y. Beaulieu, R.B. Lennox, P. Grutter, Surface stress, kinetics, and structure of alkanethiol self-assembled monolayers, Langmuir 20 (2004) 7090-7096.

[3] P. Jiang, S. Porsgaard, F. Borondics, M. Koeber, A. Caballero, H. Bluhm, F. Besenbacher, M. Salmeron, Room-temperature reaction of oxygen with gold: An In situ ambient-pressure X-ray photoelectron spectroscopy investigation, Journal of the American Chemical Society 132 (2010) 2858.

[4] H.F. Ji, B.D. Armon, Approaches to Increasing Surface Stress for Improving Signalto-Noise Ratio of Microcantilever Sensors, Analytical Chemistry 82 (2010) 1634-1642.

[5] N.V. Lavrik, C. A. Tipple, et al. , Gold nano-structures for transduction of biomolecular interactions into micrometer scale movements, Biomedical Microdevices 3 (2001) 35-44.

[6] N.V. Lavrik, C.A. Tipple, M.J. Sepaniak, P.G. Datskos, Enhanced chemi-mechanical transduction at nanostructured interfaces, Chemical Physics Letters 336 (2001) 371-376.

[7] C.A. Tipple, N.V. Lavrik, M. Culha, J. Headrick, P. Datskos, M.J. Sepaniak, Nanostructured microcantilevers with functionalized cyclodextrin receptor phases: Selfassembled monolayers and vapor-deposited films, Analytical Chemistry 74 (2002) 3118 3126.

[8] J.J. Headrick, M.J. Sepaniak, N.V. Lavrik, P.G. Datskos, Enhancing chemimechanical transduction in microcantilever chemical sensing by surface modification, Ultramicroscopy 97 (2003) 417-424.

[9] V. Tabard-Cossa, M. Godin, I.J. Burgess, T. Monga, R.B. Lennox, P. Grutter, Microcantilever-based sensors: Effect of morphology, adhesion, and cleanliness of the sensing surface on surface stress, Analytical Chemistry 79 (2007) 8136-8143. 
[10] J. Mertens, M. Calleja, D. Ramos, A. Taryn, J. Tamayo, Role of the gold film nanostructure on the nanomechanical response of microcantilever sensors, Journal of Applied Physics 101 (2007).

[11] N. Camillone, C.E.D. Chidsey, G. Liu, G. Scoles, Substrate dependence of the surface-structure and chain packing of docosyl mercaptan self-assembeled on the (111), (110), and (100) faces of single-crystal gold, Journal of Chemical Physics 98 (1993) 4234-4245.

[12] H.C. Cheng, Y.C. Hsu, C.H. Wu, W.H. Chen, Molecular dynamics study of interfacial bonding strength of self-assembled monolayer-coated Au-epoxy and $\mathrm{Au}-\mathrm{Au}$ systems, Applied Surface Science 257 (2011) 8665-8674.

[13] L.H. Dubois, B.R. Zegarski, R.G. Nuzzo, Molecular ordering of organosulfur compunds on au(111) and au(100) - adsorption from solution and in ultrahigh-vacuum, Journal of Chemical Physics 98 (1993) 678-688.

[14] C. Vericat, M.E. Vela, R.C. Salvarezza, Self-assembled monolayers of alkanethiols on $\mathrm{Au}(111)$ : surface structures, defects and dynamics, Physical Chemistry Chemical Physics 7 (2005) 3258-3268.

[15] C. Vericat, M.E. Vela, G. Benitez, P. Carro, R.C. Salvarezza, Self-assembled monolayers of thiols and dithiols on gold: new challenges for a well-known system, Chemical Society Reviews 39 (2010) 1805-1834.

[16] J.C. Love, L.A. Estroff, J.K. Kriebel, R.G. Nuzzo, G.M. Whitesides, Self-assembled monolayers of thiolates on metals as a form of nanotechnology, Chemical Reviews 105 (2005) 1103-1169.

[17] W.D. Luedtke, U. Landman, Structure and thermodynamics of self-assembled monolayers on gold nanocrystallites, Journal of Physical Chemistry B 102 (1998) 65666572 .

[18] Y. Golan, L. Margulis, I. Rubinstein, Vacuum-deposited gold-films .1. Factors affecting the film morphology, Surface Science 264 (1992) 312-326.

[19] C. Masens, J. Schulte, M. Phillips, S. Dligatch, Ultra flat gold surfaces for use in chemical force microscopy: Scanning probe microscopy studies of the effect of preparation regime on surface morphology, Microscopy and Microanalysis 6 (2000) 113120. 
[20] J.L. Plaza, S. Jacke, Y. Chen, R.E. Palmer, Annealing effects on the microstructure of sputtered gold layers on oxidized silicon investigated by scanning electron microscopy and scanning probe microscopy, Philosophical Magazine 83 (2003) 1137-1142.

[21] V.L.D.L. Santos, D. Lee, J. Seo, F. Lizbet Leon, D. Angel Bustamante, S. Suzuki, Y. Majima, T. Mitrelias, A. Ionescu, C.H.W. Barnes, Crystallization and surface morphology of $\mathrm{Au} / \mathrm{SiO}(2)$ thin films following furnace and flame annealing, Surface Science 603 (2009) 2978-2985.

[22] F. Ruffino, M.G. Grimaldi, Atomic force microscopy study of the growth mechanisms of nanostructured sputtered $\mathrm{Au}$ film on $\mathrm{Si}(111)$ : Evolution with film thickness and annealing time, Journal of Applied Physics 107 (2010).

[23] Z. Sun, J. Lue, X. Song, Microstructure and electrical properties of ultrathin gold films prepared by DC sputtering, Vacuum 85 (2010) 297-301.

[24] K. Chan, Z. Aspanut, B. Goh, C. Sow, B. Varghese, S.A. Rahman, M.R. Muhamad, Effects of post-thermal annealing temperature on the optical and structural properties of gold particles on silicon suboxide films, Applied Surface Science 257 (2011) 2208-2213.

[25] S.M. Rossnagel, Thin film deposition with physical vapor deposition and related technologies, Journal of Vacuum Science \& Technology A 21 (2003) S74-S87.

[26] J.E. Mahan, Physical vapor depsoition of thin films (Wiley, New York, 2000).

[27] J. Rideout, Analysis of the effect of sputtering parameters on the grain size of thin $\mathrm{Cu}$ films on $\mathrm{Si}(001)$ substrates, Hounours Thesis, (Memorial University of Newfoundland, St.John's, 2007).

[28] C. Buzea, K. Robbie, State of the art in thin film thickness and deposition rate monitoring sensors, Reports on Progress in Physics 68 (2005) 385-409.

[29] M.K. Kiyotaka Wasa, Hideaki Adachi, Thin film materials technology: sputtering of compund materials (William Andrew Pub., Norwich, NY, 2004).

[30] G.H. Gilmer, H.C. Huang, C. Roland, Thin film deposition: fundamentals and modeling, Computational Materials Science 12 (1998) 354-380.

[31] C.V. Thompson, Structure evolution during processing of polycrystalline films, Annual Review of Materials Science 30 (2000) 159-190. 
[32] H. Van kranenburg, C. Lodder, Tailoring growth and local composition by obliqueincidence deposition - A review and new experimental-data, Materials Science \& Engineering R-Reports 11 (1994) 295-354.

[33] H.J.H. Ernst Meyer, Roland Bennewitz, Scanning probe microscopy: the lab on a tip (Springer, Berlin, 2004).

[34] C.M. Mate, Tribology on the small scale: a bottom up approach to friction, lubrication, and wear (Oxford University Press, Oxford, 2008).

[35] E.R.B. Michael M. Khonsari, Applied tribology: bearing design and lubrication (John Wiley, New York, 2001).

[36] B. Bhushan, Modern Tribology Handbook (CRC Press, Boca Raton, FL, 1949).

[37] K.J. Stout, Development of methods for the characterisation of roughness in three dimensions, (Penton Press, London, 2000).

[38] D.R. Wissing, D. Timm, Statistics for the nonstatistician: Part I, Southern Medical Journal 105 (2012) 126-130.

[39] J.M. Nel, C.M. Demanet, K.T. Hillie, F.D. Auret, H.L. Gaigher, Using scanning force microscopy (SFM) to investigate various cleaning procedures of different transparent conducting oxide substrates, Applied Surface Science 134 (1998) 22-30.

[40] D.Y. Petrovykh, H. Kimura-Suda, A. Opdahl, L.J. Richter, M.J. Tarlov, L.J. Whitman, Alkanethiols on platinum: Multicomponent self-assembled monolayers, Langmuir 22 (2006) 2578-2587.

[41] H.L. Skriver, N.M. Rosengaard, Surface-energy and work function of elemental metals, Physical Review B 46 (1992) 7157-7168.

[42] J.A. Floro, S.J. Hearne, J.A. Hunter, P. Kotula, E. Chason, S.C. Seel, C.V. Thompson, The dynamic competition between stress generation and relaxation mechanisms during coalescence of Volmer-Weber thin films, Journal of Applied Physics 89 (2001) 4886-4897.

[43] D. Porath, Y. Goldstein, A. Grayevsky, O. Millo, Scanning-tunneling-microscopy studies of annealing of gold-films, Surface Science 321 (1994) 81-88.

[44] N.A. Alcantar, C. Park, J.M. Pan, J.N. Israelachvili, Adhesion and coalescence of ductile metal surfaces and nanoparticles, Acta Materialia 51 (2003) 31-47. 
[45] M. Kawasaki, Contribution of low-energy ion bombardment to the growth of atomically flat $\mathrm{Ag}(111)$ and $\mathrm{Au}(111)$ films by glow discharge sputtering, Applied Surface Science 135 (1998) 115-120.

[46] S.-Y. Chin, Effect of Target Bias Voltage on Gold Films Using Plasma Based Ion Implantation, Journal of the Korean Physical Society 52 (2008) 1227-1230.

[47] F. Katzenberg, R. Janlewing, J. Petermann, Surface diffusion of metal atoms on polymer substrates during physical vapour deposition, Colloid and Polymer Science 278 (2000) 280-284.

[48] K.-Y. Chan, B.-S. Tee, Atomic force microscopy (AFM) and X-ray diffraction (XRD) investigations of copper thin films prepared by dc magnetron sputtering technique, Microelectronics Journal 37 (2006) 1064-1071.

76 


\section{Appendix A}

\section{The Developed Surface-Area Ratio}

The area of the sample $A$ can be estimated by triangulating fracture-surface topographic data, as shown in Figure $\mathrm{A}$, and taking the total of all triangular element areas $A_{i j}$. Because the four corners of the rectangular plane may not be at the same height, the interfacial area of the smallest sampling rectangle ABCD at $\left(x_{i}, y_{j}\right)(i=1, \ldots, M-1 ; j=1$, $\ldots, N-1$ ) may be considered to consist of the average of two sets of triangular areas, $(\mathrm{ABC}$ and $\mathrm{ACD})$ and $(\mathrm{ABD}$ and $\mathrm{BCD})[37]$ :

$$
\begin{aligned}
A_{i j} & =\frac{1}{2}\left[\left(\frac{1}{2}|\overrightarrow{B A} \times \overrightarrow{B C}|+\frac{1}{2}|\overrightarrow{D A} \times \overrightarrow{D C}|\right)+\left(\frac{1}{2}|\overrightarrow{A B} \times \overrightarrow{A D}|+\frac{1}{2}|\overrightarrow{C B} \times \overrightarrow{C D}|\right)\right] \\
& =\frac{1}{4}(|\overrightarrow{A B}|+|\overrightarrow{C D}|)+(|\overrightarrow{A D}|+|\overrightarrow{B C}|) \\
= & \frac{1}{4}\left\{\begin{array}{l}
\left(\left[\Delta y^{2}+\left(z\left(x_{i}, y_{j}\right)-z\left(x_{i}, y_{j+1}\right)\right)^{2}\right]^{\frac{1}{2}}+\left[\Delta y^{2}+\left(z\left(x_{i+1}, y_{j+1}\right)-z\left(x_{i+1}, y_{j}\right)\right)^{2}\right]^{\frac{1}{2}}\right) \cdot \\
\left(\left[\Delta x^{2}+\left(z\left(x_{i}, y_{j}\right)-z\left(x_{i}, y_{j+1}\right)\right)^{2}\right]^{1 / 2}+\left[\Delta x^{2}+\left(z\left(x_{i}, y_{j+1}\right)-z\left(x_{i+1}, y_{j+1}\right)\right)^{2}\right]^{1 / 2}\right)
\end{array}\right\},
\end{aligned}
$$

where $z_{i, j}=z\left(x_{i}, y_{j}\right)$ is the surface height at the position $\left(x_{i}, y_{j}\right)$.

Because the area of the sample is expressed by:

$$
A=\sum_{j=1}^{N-1} \sum_{i=1}^{M-1} A_{i j},
$$

the developed surface-area ratio becomes: 


$$
S d r=\left(\frac{\text { Area of the Sample }- \text { Area of the substrate }}{\text { Area of the substrate }}\right) \times 100 \% .
$$

The $S d r$ is given by:

$$
S d r=\frac{\sum_{j=1}^{N-1} \sum_{i=1}^{M-1} A_{i j}-(M-1)(N-1) \Delta x \cdot \Delta y}{(M-1)(N-1) \Delta x \cdot \Delta y} \cdot 100 \%,
$$

where $\Delta x$ is the sampling step along the $x$-axis, and $\Delta y$ is the sampling step along the $y$ axis.

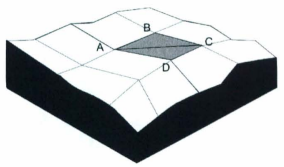

Figure A: Schematic of the developed area surface-area ratio. 

